Article

\title{
Synthesis and Antimicrobial Evaluation of Side-Chain Derivatives based on Eurotiumide A
}

\author{
Atsushi Nakayama ${ }^{1, *}$, Hideo Sato ${ }^{1}$, Tenta Nakamura ${ }^{1}$, Mai Hamada ${ }^{1}$, Shuji Nagano ${ }^{1}$, \\ Shuhei Kameyama ${ }^{1}$, Yui Furue ${ }^{2}$, Naoki Hayashi ${ }^{2}$, Go Kamoshida ${ }^{2}$, Sangita Karanjit ${ }^{1}$, \\ Masataka Oda ${ }^{2}$ D and Kosuke Namba ${ }^{1, *}$ \\ 1 Graduate School of Pharmaceutical Sciences and Research Cluster on "Innovative Chemical Sensing", \\ Tokushima University, 1-78-1 Shomachi, Tokushima 770-8505, Japan; hideo1995214@gmail.com (H.S.); \\ c401603069@tokushima-u.ac.jp (T.N.); c401403070@tokushima-u.ac.jp (M.H.); \\ c401941004@tokushima-u.ac.jp (S.N.); c401931030@tokushima-u.ac.jp (S.K.); \\ karanjit@tokushima-u.ac.jp (S.K.) \\ 2 Department of Microbiology and Infection Control Sciences, Kyoto Pharmaceutical University, \\ Misasaginakauchi-cho, Yamashita-Ku, Kyoto 607-8414, Japan; mametty1214@gmail.com (Y.F.); \\ nhayashi@mb.kyoto-phu.ac.jp (N.H.); kamoshida@mb.kyoto-phu.ac.jp (G.K.); \\ moda@mb.kyoto-phu.ac.jp (M.O.) \\ * Correspondence: anakaya@tokushima-u.ac.jp (A.N.); namba@tokushima-u.ac.jp (K.N.)
}

Received: 30 November 2019; Accepted: 29 January 2020; Published: 30 January 2020

\begin{abstract}
Side-chain derivatives of eurotiumide A, a dihydroisochroman-type natural product, have been synthesized and their antimicrobial activities described. Sixteen derivatives were synthesized from a key intermediate of the total synthesis of eurotiumide A, and their antimicrobial activities against two Gram-positive bacteria, methicillin-susceptible and methicillin-resistant Staphylococcus aureus (MSSA and MRSA), and a Gram-negative bacterium, Porphyromonas gingivalis, were evaluated. The results showed that derivatives having an iodine atom on their aromatic ring instead of the prenyl moiety displayed better antimicrobial activity than eurotiumide A against MSSA and P. gingivalis. Moreover, we discovered that a derivative with an isopentyl side chain, which is a hydrogenated product of eurotiumide $\mathrm{A}$, is the strongest antimicrobial agent against all three strains, including MRSA.
\end{abstract}

Keywords: antibiotics; natural product; $P$. gingivalis; methicillin-resistant S. aureus

\section{Introduction}

Humans have always struggled against infectious diseases [1-5] and in relatively recent times have developed various antimicrobial therapies [6-8]. Since the discovery of penicillin [9], various natural products having antimicrobial activity have been discovered [10-16], and the majority of clinically used antibiotics are either natural products, semisynthetic derivatives, or compounds derived from them [17-19]. Despite the presence of many excellent antibiotics, multidrug-resistant bacterial pathogens have emerged all over the world [20-22], and the development of novel and effective antimicrobial agents against many kinds of pathogenic bacteria, including methicillin-resistant Staphylococcus aureus (MRSA), should remain a continuous mission for medicinal chemists. In 2014, Wang and co-workers discovered eurotiumides, which are novel dihydroisocoumarin-type natural products, from a gorgonian-derived fungus, Eurotium sp. XS-200900E6 [23]. Among the series of eurotiumides, eurotiumide A (1), having cis configurations at H3/H4, exhibited potent antimicrobial activities against Staphylococcus epidermidis, Bacillus cereus, Vibrio anguillarum, and Escherichia coli. Based on that report, although 1 seems to be an attractive seed compound for antibiotics, further antimicrobial investigation and a structure-activity relationship study of $\mathbf{1}$ are needed. In particular, because there is a chance that modification of the side chain of the aromatic ring could improve antimicrobial activity 
and the spectrum, a structure-activity relationship study of the substituent effect of the aromatic ring is essential for discovering promising candidates for antimicrobial agents. Recently, we reported the first asymmetric total syntheses of (-)-eurotiumide A (1) and (+)-eurotiumide B and revised their reported structures [24]. In our synthetic route, the prenyl side chain of the aromatic ring was introduced in the late stage by the Stille coupling reaction with the key intermediate 2 . Based on our previous results, we considered that a number of derivatives of $\mathbf{1}$, which have a variety of kinds of side-chain moiety, could be obtained from the common intermediate 2 and non-substituted compound 3 in the late stage of synthesis (Figure 1).

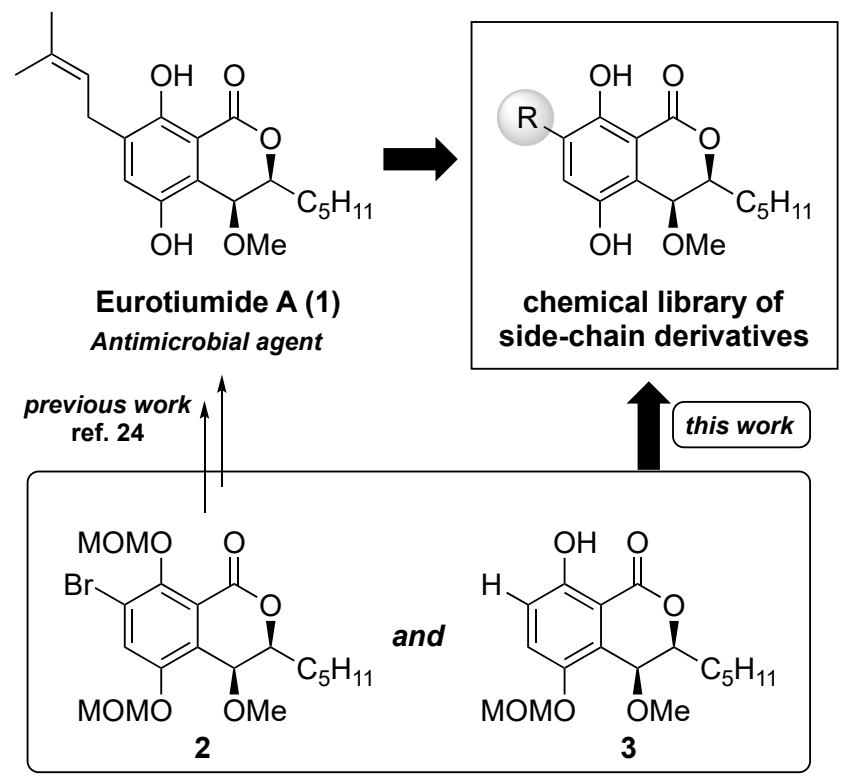

Figure 1. Concept of construction of the chemical library of the side chain-derivatives of eurotiumide A (1).

In this work, as part of our continuing research [24,25], we constructed a chemical library of the side-chain derivatives of eurotiumide A (1) to elucidate the effects of the side chains of the aromatic rings and to develop antimicrobial agents against methicillin-susceptible S. aureus (MSSA) and methicillin-resistant S. aureus (both Gram-positive bacteria), as well as Porphyromonas gingivalis (a Gram-negative bacterium).

\section{Results and Discussion}

\subsection{Synthesis of the Side-Chain Derivatives of Eurotiumide A}

Our synthetic plan is shown in Figure 2. We planned to introduce three types of functional groups: a hydrocarbon group, including hydrogen, alkyl, and aromatic rings (Type A); a heteroatom and heteroatom-containing alkyl group (Type B); and halogen atoms group (Type C). The derivatives of groups $\mathrm{A}$ and $\mathrm{B}$ could be derived from 2 by the cross-coupling reaction and functional group transformation. The halogenated derivatives (Type C) would be obtained from 3 by direct introduction of the halogen atoms. Although Wang et al. isolated the natural eurotiumide A (1) as a racemic form, they evaluated the antimicrobial activities of its enantiomers after separation by chiral HPLC and revealed that there was no significant difference between the enantiomers [23]. From the viewpoint of the efficiency of compound supply, we decided to make racemic compounds. 


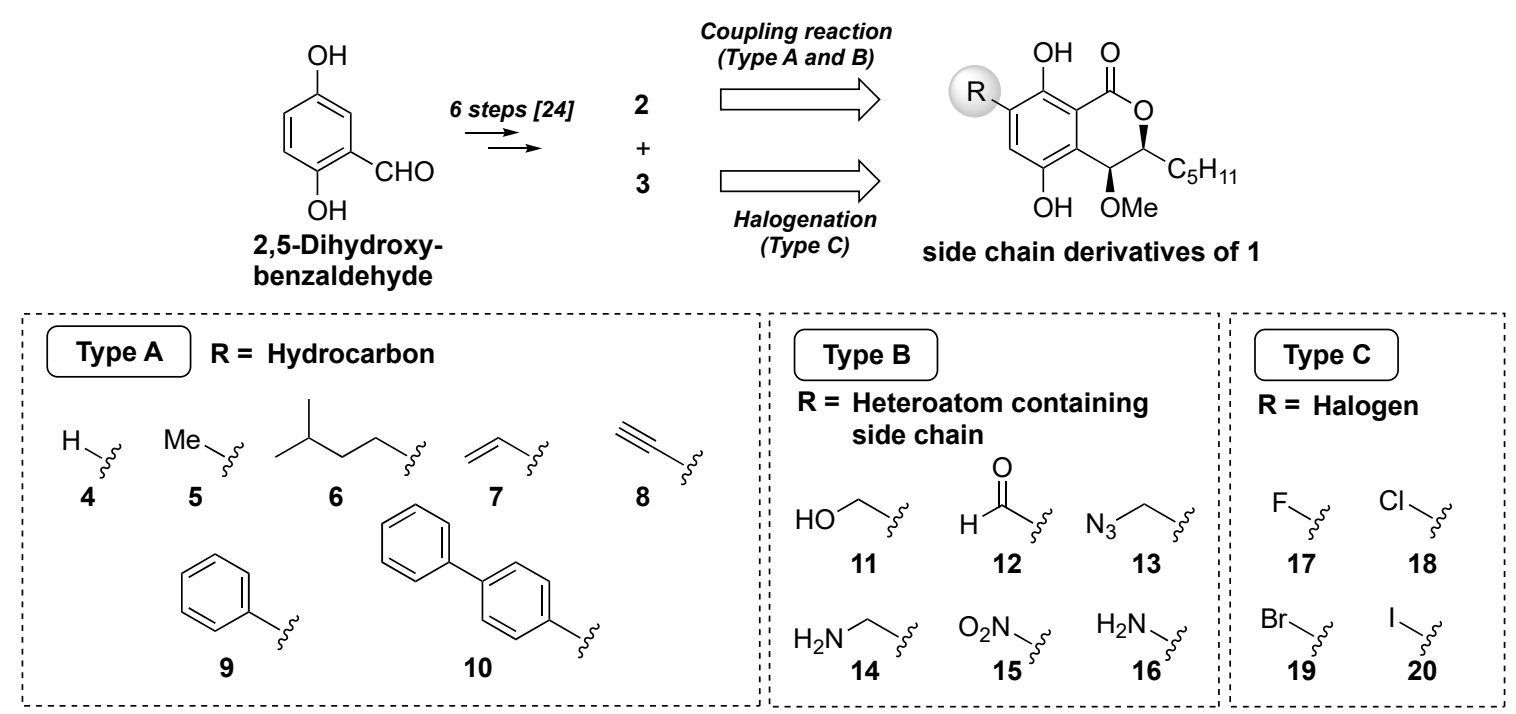

Figure 2. Synthetic plan of the side-chain derivatives of eurotiumide A (1).

First, we initiated the syntheses of the derivatives of group A (Scheme 1). The non-substituted derivative 4 was obtained from 3 by deprotection of the diMOM group with aqueous $6 \mathrm{M} \mathrm{HCl}$ in methanol at $40{ }^{\circ} \mathrm{C}$ in $79 \%$ yield. Catalytic hydrogenation of eurotiumide A (1) gave the isopentyl derivative 6 in quantitative yield. Methyl and vinyl groups were introduced by the Stille coupling reaction with 2 to afford methyl derivative $5 \mathbf{a}$ and styrene derivative $7 \mathrm{a}$ in $83 \%$ and quantitative yields, respectively. Phenyl derivative 9a and biphenyl derivative 10a were obtained from 2 by the Suzuki-Miyaura cross coupling reaction with the corresponding boronic acids in $75 \%$ and $77 \%$ yields, respectively. Deprotection of the diMOM group of derivatives $5 \mathbf{a}, 7 \mathbf{a}, \mathbf{9 a}$, and $\mathbf{1 0 a}$ then gave the corresponding desired products $(5,7,9$, and $\mathbf{1 0})$. We tried to introduce the alkyne group by the Sonogashira coupling reaction; however, the desired alkyne product was obtained in only $12 \%$ yield. To improve the reaction yield, the Seyferth-Gilbert homologation using the Ohira-Bestmann reagent 21 was applied to the aldehyde derivative 12a (vide infra) and afforded the desired alkyne 8a in quantitative yield. After acidic treatment of $8 a$, the alkyne derivative 8 was obtained in $68 \%$ yield.

With type A derivatives in hand, we turned our attention to preparing type B derivatives having heteroatom-containing side chains (Scheme 2). For the introduction of an alkyl group containing heteroatoms, we chose the styrene derivative $7 \mathbf{a}$ as a starting point. Ozonolysis of the alkene moiety of $7 \mathbf{a}$ afforded the diMOM-protected benzaldehyde 12a in excellent yield. Acidic treatment of 12a gave the desired deprotected benzaldehyde derivative 12 in $77 \%$. On the other hand, reduction of the aldehyde moiety of 12a with sodium borohydride to give the benzyl alcohol 11a and the deprotection furnished the hydroxymethyl derivative $\mathbf{1 1}$ in moderate yield. To introduce a nitrogen group at the benzyl position of 11a, the primary alcohol moiety was converted to a mesyl group (22) and a nucleophilic substitution reaction with sodium azide afforded diMOM-protected azide 13a in good yield. Derivative 13a was treated with aqueous $6 \mathrm{M} \mathrm{HCl}$ in $\mathrm{MeOH}$ to furnish the desired dihydroxy azide derivative $\mathbf{1 3}$. We then tried to convert the azide into an amine functionality. After several attempts, we found that addition of triethylamine was crucial to keep the reaction clean and we succeeded to get 14a. Then, deprotection of the diMOM group gave the desired aminomethyl derivative $\mathbf{1 4}$. 


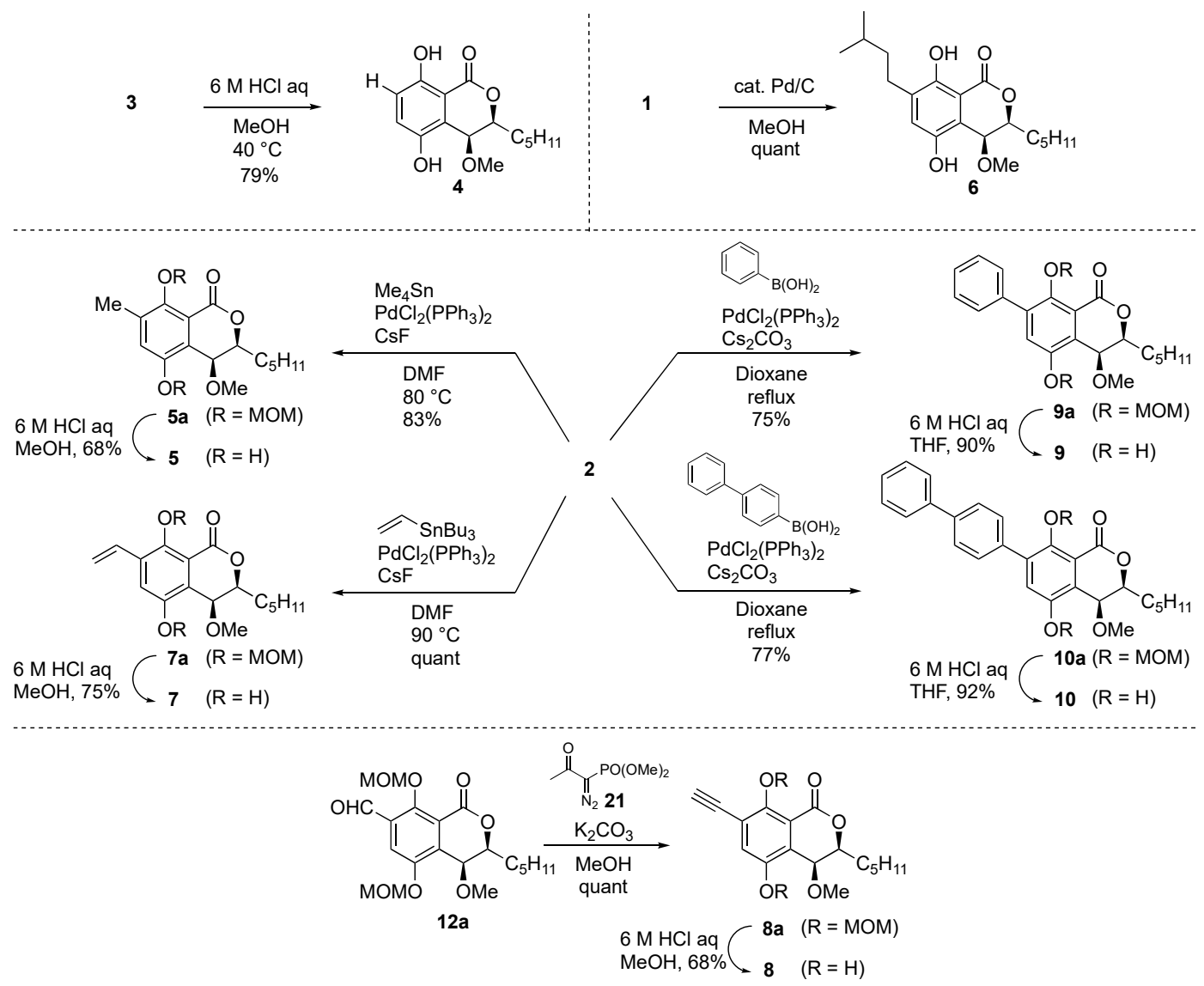

Scheme 1. Synthesis of the hydrocarbon derivatives (type A).
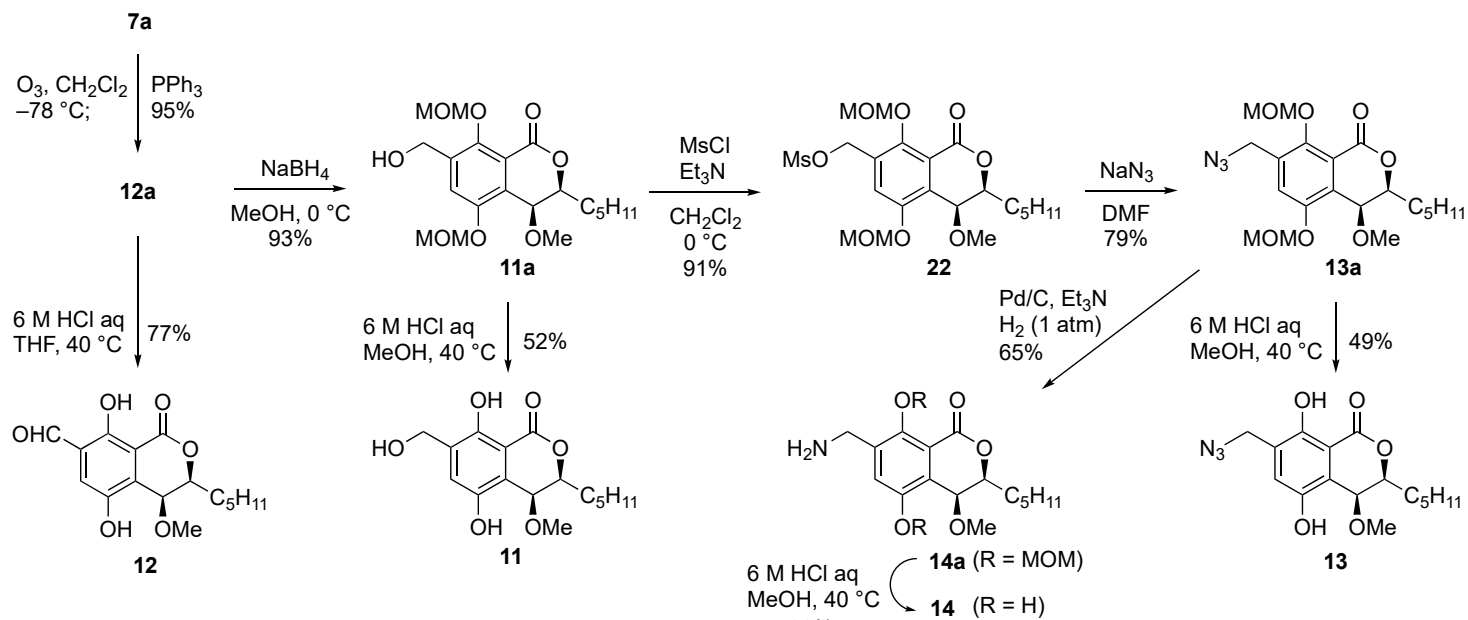

$32 \%$

Scheme 2. Synthesis of the derivatives having heteroatom-containing side chains (type B).

Next, a nitration reaction was conducted with non-substituted derivative 3 by adding $\mathrm{HNO}_{3}$ in $\mathrm{AcOH}$ to afford monoMOM-protected nitro derivative 15a as a crude product; then it was deprotected under acidic condition to give the nitro derivative $\mathbf{1 5}$ (Scheme 3). After that, hydrogenation with Adam's catalyst produced the aniline derivative 16 from 15. 


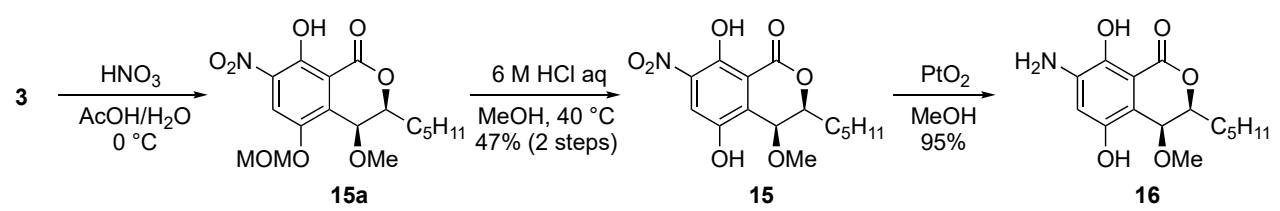

Scheme 3. Synthesis of nitro and aniline derivatives.

Finally, we tried to synthesize the halogenated derivatives (Scheme 4). Chloro and iodo groups were introduced to treat 3 with $\mathrm{N}$-chlorosuccinimide and $\mathrm{N}$-iodosuccinimide in DMF to afford the chloro derivative 18a and the iodo derivative 20a, respectively. The diMOM groups of 18a and 20a were then deprotected under acidic conditions to afford the desired $\mathbf{1 8}$ and $\mathbf{2 0 .}$. Bromo derivative 19 was obtained from 2 in $97 \%$ yield by acid treatment to cleave the diMOM group. However, despite several efforts to introduce fluorine to the aromatic ring from 3 , we could not get the desired fluoro derivative 17. We also tried the Sandmeyer reaction with 16 but did not obtain the desired 17.

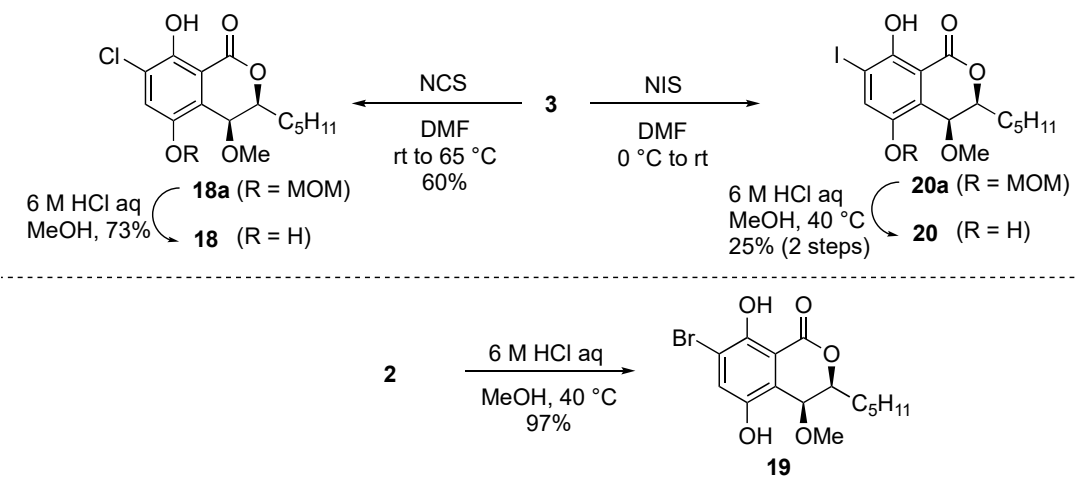

Scheme 4. Synthesis of halogenated derivatives (type C).

\subsection{Antimicrobial Evaluation of Synthesized Derivatives}

After the initially set derivatives of eurotiumide A were synthesized, the first antimicrobial activity screening was conducted against the Gram-positive MSSA and MRSA as well as the Gram-negative $P$. gingivalis in $10 \mu \mathrm{M}$ solutions of the synthesized derivatives to narrow down the promising antimicrobial candidates. The results are depicted in Figure 3. (+/-)-Eurotiumide A (1) exhibited mild antimicrobial activity against MSSA at this concentration (Figure 3a). While most of the derivatives did not show antimicrobial activity against this strain, the isopentyl derivative 6 and the iodo derivative 20 exhibited more potent antimicrobial activity than $\mathbf{1}$. Next, we tested the same screening against MRSA (Figure $3 \mathrm{~b}$ ). Most of the derivatives that displayed good activity against MSSA showed no antimicrobial activity against MRSA. Even natural product $\mathbf{1}$ and the iodo derivative $\mathbf{2 0}$ also did not show good antimicrobial activity against MRSA. Surprisingly, only the isopentyl derivative $\mathbf{6}$, which was a reduced derivative of $\mathbf{1}$, was found to have good antimicrobial activity against MRSA. We also conducted antimicrobial screening against $P$. gingivalis (Figure 3c). Unlike the case with $S$. aureus, many derivatives, specifically eurotiumide $A(\mathbf{1})$, isopentyl derivative $\mathbf{6}$, vinyl derivative 7 , aniline derivative 16, and three halogenated derivatives $(\mathbf{1 8}, \mathbf{1 9}, \mathbf{2 0})$, were effective against $P$. gingivalis. 
(a) methicillin-susceptible $S$. aureus

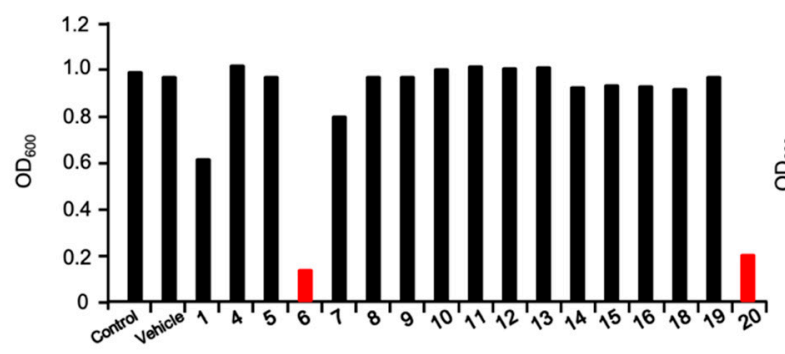

(b) methicillin-resistant $S$. aureus

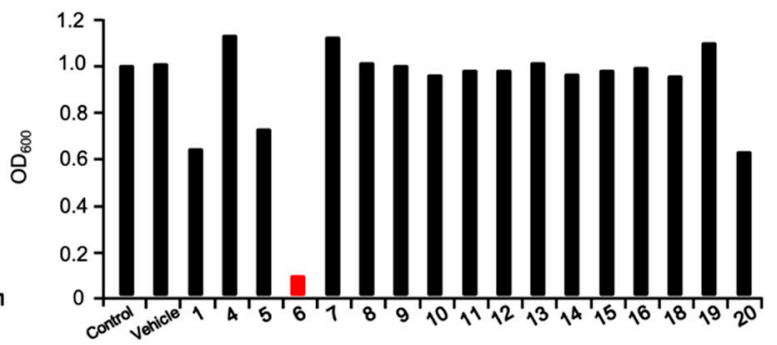

(c) P. gingivalis

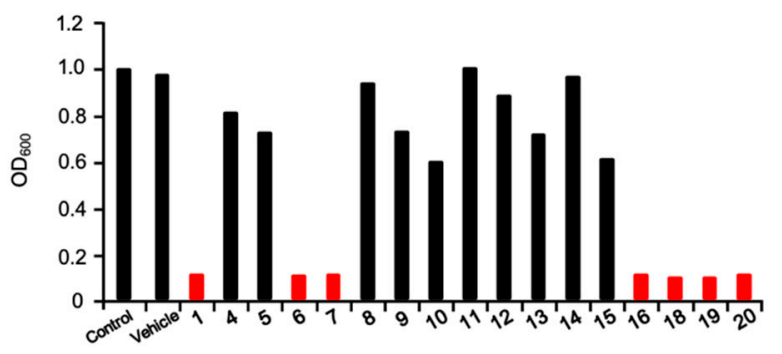

Figure 3. Initial screening of antimicrobial activity against (a) methicillin-susceptible S. aureus, (b) methicillin-resistant S. aureus, and (c) P. gingivalis. The terminal concentration was $10 \mu \mathrm{M}$.

Since we acquired promising agents against all three strains, we determined the $\mathrm{IC}_{50}$ values of these candidates (Table 1). The $\mathrm{IC}_{50}$ values of the isopentyl derivative $\mathbf{6}$ and the iodo derivative 20 against MSSA were $5.6 \mu \mathrm{M}(2.0 \mu \mathrm{g} / \mathrm{mL})$ and $9.0 \mu \mathrm{M}(3.7 \mu \mathrm{g} / \mathrm{mL})$, respectively. Moreover, the $\mathrm{IC}_{50}$ value of 6 against MRSA was $4.3 \mu \mathrm{M}(1.5 \mu \mathrm{g} / \mathrm{mL})$, which is the same level of activity against MSSA. The IC $_{50}$ values of these seven candidates $(\mathbf{1}, \mathbf{6}, \mathbf{7}, \mathbf{1 6}, \mathbf{1 8}, \mathbf{1 9}$, and 20) against $P$. gingivalis ranged from 2.0 to $7.0 \mu \mathrm{M}$. We also checked the cytotoxicity of three compounds $(\mathbf{1}, \mathbf{6}$, and $\mathbf{2 0})$ against the A549 cell line, and these three compounds were non-toxic in $10 \mu \mathrm{M}$.

Table 1. The $\mathrm{IC}_{50}$ values $(\mu \mathrm{M})$ of the selected side chain derivatives against methicillin-susceptible $S$. aureus (MSSA), methicillin-resistant $S$. aureus (MRSA), and P. gingivalis. Vancomycin (VCM) was used as a positive control against MSSA and MRSA. Cefcapene pivoxyl (CFPN-PI) was used as a positive control against $P$. gingivalis.

\begin{tabular}{cccccccccc}
\hline Strains & $\mathbf{1}$ & $\mathbf{6}$ & $\mathbf{7}$ & $\mathbf{1 6}$ & $\mathbf{1 8}$ & $\mathbf{1 9}$ & $\mathbf{2 0}$ & VCM & CFPN-PI \\
\hline $\begin{array}{c}\text { Methicillin-susceptible } \\
\text { S. aureus (MSSA) }\end{array}$ & - & 5.6 & - & - & - & - & 9.0 & 1.3 & - \\
\hline $\begin{array}{c}\text { Methicillin-resistant } \\
\text { S. aureus (MRSA) }\end{array}$ & - & 4.3 & - & - & - & - & - & 1.5 & - \\
\hline$\quad$ P. gingivalis & 3.6 & 2.0 & 3.5 & 6.7 & 6.4 & 7.0 & 3.5 & - & 0.03 \\
\hline
\end{tabular}

In this study, we discovered that the isopentyl derivative 6 , which is a one-point modified compound of natural product 1, and the iodo derivative 20 have superior antimicrobial activity to 1 against MSSA and P. gingivalis. Although 20 did not exhibit good efficacy against MRSA, 6 was found to maintain antimicrobial activity against these three strains, including MRSA. These results indicate that S. aureus is sensitive to changes in the side chain of the aromatic ring and that MRSA can distinguish the subtle difference between prenyl and isopentyl moieties. Moreover, the weak antimicrobial activity of $\mathbf{1}$ against MRSA suggests a binding affinity between $\mathbf{1}$ and the penicillin binding protein 2' [26], which is the main resistance mechanism of MRSA against antibiotics. The inhibition of cell wall synthesis seems to be the mode of action of $\mathbf{1}$, although a more detailed study is needed to clarify the mode of action of $\mathbf{6}$ and 20. On the other hand, we found that several compounds having alkyl and halogenated side chains well suppressed the increase in $P$. gingivalis. 


\section{Materials and Methods}

\subsection{Preparation of Eurotiumide A Derivatives.}

\subsubsection{General Procedure}

All the reactions were carried out in a round-bottomed flask with an appropriate number of necks and side arms connected to a three-way stopcock and/or a rubber septum cap under an argon atmosphere. All vessels were first evacuated by rotary pump and then flushed with argon prior to use. Solutions and solvents were introduced by hypodermic syringe through a rubber septum. During the reaction, the vessel was kept under a positive pressure of argon. Dry THF was freshly prepared by distillation from benzophenone ketyl before use. Anhydrous $\mathrm{CH}_{2} \mathrm{Cl}_{2}, \mathrm{DMF}$, ethanol, $\mathrm{MeCN}$, methanol, pyridine, and toluene were purchased from Kanto Chemical Co. Inc. Infrared (IR) spectra were recorded on a JASCO FT/IR-4100 spectrophotometer using a $5 \mathrm{~mm} \mathrm{KBr}$ plate. Wavelengths of maximum absorbance are quoted in $\mathrm{cm}^{-1}$. 1H-NMR spectra were recorded on a JEOL ECA-400 (400 MHz), Bruker AV-400N (400 MHz), and Bruker AV-500 (500 MHz) in $\mathrm{CDCl}_{3}$. Chemical shifts are reported in parts per million (ppm), and signals are expressed as singlet (s), doublet (d), triplet $(\mathrm{t})$, multiplet $(\mathrm{m})$, broad (br), and overlapped. 13C-NMR spectra were recorded on a JEOL ECA-400 (100 MHz), Bruker AV-400N (100 MHz), and Bruker AV-500 (125 MHz) in $\mathrm{CDCl}_{3}$. Chemical shifts are reported in parts per million (ppm) (see Supplementary Materials). High resolution mass (HRMS) spectra were recorded on a Thermo Scientific Exactive. All melting points were measured with a Yanaco MP-500D. Analytical thin layer chromatography (TLC) was performed using $0.25 \mathrm{~mm}$ E. Merck Silica gel (60F-254) plates. Reaction components were visualized phosphomolybdic acid or ninhydrin or $p$-anisaldehyde in 10\% sulfuric acid in ethanol. Kanto Chem. Co. Silica Gel 60N (particle size $0.040-0.050 \mathrm{~mm}$ ) was used for column chromatography.

\subsubsection{Synthesis of $(3 S, 4 S)$-5,8-dihydroxy-4-methoxy-3-pentylisochroman-1-one (4)}

To a solution of bromo compound $3(10.0 \mathrm{mg}, 30.8 \mu \mathrm{mol})$ in $\mathrm{MeOH}(2.3 \mathrm{~mL})$ was added $6 \mathrm{M}$ aqueous $\mathrm{HCl}(0.77 \mathrm{~mL})$ at $0{ }^{\circ} \mathrm{C}$. After stirring for $30 \mathrm{~min}$ at $40^{\circ} \mathrm{C}$, the reaction was quenched by adding saturated aqueous $\mathrm{NaHCO}_{3}$ at $0{ }^{\circ} \mathrm{C}$. The mixture was extracted with EtOAc $(\times 3)$ and the combined organic layers were washed with brine, dried over $\mathrm{Na}_{2} \mathrm{SO}_{4}$, filtered, and concentrated under reduced pressure. The residue was purified by preparative thin layer chromatography (PTLC) (EtOAc: $n$-hexane $=3: 7)$ to give non-substituted derivative $4(6.8 \mathrm{mg}, 79 \%)$ as a white solid. m.p. $120-121{ }^{\circ} \mathrm{C} ; 1 \mathrm{H}-\mathrm{NMR}$ $\left(400 \mathrm{MHz}, \mathrm{CDCl}_{3}\right) \delta 10.62(1 \mathrm{H}, \mathrm{s}), 7.06(1 \mathrm{H}, \mathrm{d}, J=9.0 \mathrm{~Hz}), 6.91(1 \mathrm{H}, \mathrm{d}, J=9.0 \mathrm{~Hz}), 5.89(1 \mathrm{H}, \mathrm{br}-\mathrm{s}), 4.77$ $(1 \mathrm{H}, \mathrm{d}, J=2.7 \mathrm{~Hz}), 4.50(1 \mathrm{H}, \mathrm{ddd}, J=2.7,5.4,8.3 \mathrm{~Hz}), 3.40(3 \mathrm{H}, \mathrm{s}), 1.95(1 \mathrm{H}, \mathrm{m}), 1.85(1 \mathrm{H}, \mathrm{m}), 1.70-1.50$ (1H, overlapped), $1.46(1 \mathrm{H}, \mathrm{m}), 1.40-1.25$ (4H, overlapped), $0.91(3 \mathrm{H}, \mathrm{t}, J=6.8 \mathrm{~Hz}) ; 13 \mathrm{C}-\mathrm{NMR}(100 \mathrm{MHz}$, $\left.\mathrm{CDCl}_{3}\right) \delta 169.0,156.2,145.7,125.1,121.7,118.8,107.6,81.4,69.8,56.8,31.6,29.8,24.9,22.5,14.0 . ; \mathrm{IR}(\mathrm{KBr})$ $3219,2955,2924,2860,1661,1586,1471,1293,1204,905 \mathrm{~cm}^{-1}$; HRMS (ESI) $\mathrm{m} / z(\mathrm{M}+\mathrm{Na})^{+}$calculated for $\left(\mathrm{C}_{15} \mathrm{H}_{20} \mathrm{O}_{5} \mathrm{Na}\right)^{+}$303.1208, found 303.1200 .

\subsubsection{Synthesis of (3S,4S)-5,8-dihydroxy-7-isopentyl-4-methoxy-3-pentylisochroman-1-one (6)}

To a solution of eurotiumide A (1) $(1.6 \mathrm{mg}, 4.6 \mu \mathrm{mol})$ in $\mathrm{MeOH}(0.23 \mathrm{~mL})$ was added $\mathrm{Pd} / \mathrm{C}(1.6 \mathrm{mg}$, $100 \mathrm{w} / \mathrm{w} \%$ ) at room temperature. After stirring for $1.5 \mathrm{~h}$ under hydrogen atmosphere (balloon), the reaction mixture was passed through Celite and the organic solvent was removed under reduced pressure. The residue was purified with flash column chromatography (EtOAc: $n$-hexane $=2: 3$ ) to give isopentyl derivative $6(1.4 \mathrm{mg}, 88 \%)$ as a white wax. 1H-NMR $\left(500 \mathrm{MHz}, \mathrm{CDCl}_{3}\right) \delta 10.91(1 \mathrm{H}, \mathrm{s}), 6.93$ $(1 \mathrm{H}, \mathrm{s}), 5.62(1 \mathrm{H}, \mathrm{br}-\mathrm{s}), 4.74(1 \mathrm{H}, \mathrm{d}, J=2.5 \mathrm{~Hz}), 4.48(1 \mathrm{H}, \mathrm{ddd}, J=2.6,5.4,8.6 \mathrm{~Hz}), 3.38(3 \mathrm{H}, \mathrm{s}), 2.62$ $(2 \mathrm{H}, \mathrm{m}), 1.95(1 \mathrm{H}, \mathrm{m}), 1.85(1 \mathrm{H}, \mathrm{m}), 1.65-1.50(2 \mathrm{H}$, overlapped $), 1.50-1.40$ (3H, overlapped), $1.40-1.30$ (4H, overlapped), $0.95(6 \mathrm{H}, \mathrm{d}, J=6.3 \mathrm{~Hz}), 0.90(3 \mathrm{H}, J=6.9 \mathrm{~Hz}) ; 13 \mathrm{C}-\mathrm{NMR}\left(125 \mathrm{MHz}, \mathrm{CDCl}_{3}\right) \delta 169.4$, 154.7, 145.0, 133.6, 124.8, 118.6, 106.8, 81.4, 69.9, 56.6, 38.4, 31.6, 29.8, 29.7, 27.9, 27.5, 14.9, 22.5, 14.0.; 
IR (KBr) 3290, 2956, 2927, 2870, 1761, 1445, 1171, $807 \mathrm{~cm}^{-1}$; HRMS (ESI) $m / z(\mathrm{M}+\mathrm{H})^{+}$calculated for $\left(\mathrm{C}_{20} \mathrm{H}_{31} \mathrm{O}_{5}\right)^{+}$351.2171, found 351.2177.

\subsection{4. (3S,4S)-4-methoxy-5,8-bis(methoxymethoxy)-7-methyl-3-pentylisochroman-1-one (5a)}

To a solution of bromo compound $3(40.0 \mathrm{mg}, 89.4 \mu \mathrm{mol})$ and $\mathrm{CsF}(16.3 \mathrm{mg}, 107 \mu \mathrm{mol})$ in degassed DMF $(0.45 \mathrm{~mL})$ were added $\mathrm{Me}_{4} \mathrm{Sn}(15 \mu \mathrm{L}, 107 \mu \mathrm{mol})$ and $\mathrm{PdCl}_{2}\left(\mathrm{PPh}_{3}\right)_{2}(6.3 \mathrm{mg}, 8.94 \mu \mathrm{mol})$ at room temperature. After stirring for $50 \mathrm{~min}$ at $80{ }^{\circ} \mathrm{C}$, the reaction was quenched by adding water. The mixture was extracted with EtOAc $(\times 3)$ and the combined organic layers were washed with brine, dried over $\mathrm{Na}_{2} \mathrm{SO}_{4}$, filtered, and concentrated under reduced pressure. The residue was purified with flash column chromatography (EtOAc: $n$-hexane $=3: 7$ ) to give diMOM-protected methyl derivative $\mathbf{5 a}$ $(28.5 \mathrm{mg}, 83 \%)$ as a yellow amorphous. $1 \mathrm{H}-\mathrm{NMR}\left(400 \mathrm{MHz}, \mathrm{CDCl}_{3}\right) \delta 7.255(1 \mathrm{H}, \mathrm{s}), 5.21(2 \mathrm{H}, \mathrm{s}), 5.10$ $(1 \mathrm{H}, \mathrm{d}, J=6.8 \mathrm{~Hz}), 5.07(1 \mathrm{H}, \mathrm{d}, J=6.8 \mathrm{~Hz}), 4.59(1 \mathrm{H}, \mathrm{d}, J=1.5 \mathrm{~Hz}), 4.26(1 \mathrm{H}, \mathrm{ddd}, J=1.5,5.9,7.5 \mathrm{~Hz})$, $3.60(3 \mathrm{H}, \mathrm{s}), 3.50(3 \mathrm{H}, \mathrm{s}), 3.30(3 \mathrm{H}, \mathrm{s}), 2.39(3 \mathrm{H}, \mathrm{s}), 2.02(1 \mathrm{H}, \mathrm{m}), 1.81(1 \mathrm{H}, \mathrm{m}), 1.70-1.50(1 \mathrm{H}$, overlapped), $1.43(1 \mathrm{H}, \mathrm{m}), 1.40-1.25$ (4H, overlapped), $0.91(3 \mathrm{H}, \mathrm{t}, J=6.8 \mathrm{~Hz})$; 13C-NMR (125 MHz, $\left.\mathrm{CDCl}_{3}\right) \delta 162.4$, 152.3, 149.8, 135.7, 126.3, 121.3, 118.7, 101.5, 95.0, 80.9, 68.2, 57.5, 56.7, 56.4, 31.6, 30.6, 24.9, 22.6, 17.6, 14.0.; IR (KBr) 2958, 2927, 2858, 2828, 1728, 1478, $1153 \mathrm{~cm}^{-1}$; HRMS (ESI) $m / z(\mathrm{M}+\mathrm{H})^{+}$calculated for $\left(\mathrm{C}_{20} \mathrm{H}_{31} \mathrm{O}_{7}\right)^{+}$383.2070, found 383.2069.

\subsection{5. (3S,4S)-5,8-dihydroxy-4-methoxy-7-methyl-3-pentylisochroman-1-one (5)}

To a solution of diMOM-protected methyl derivative $\mathbf{5 a}(10.0 \mathrm{mg}, 26.0 \mu \mathrm{mol})$ in $\mathrm{MeOH}(2.0 \mathrm{~mL})$ was added $6 \mathrm{M}$ aqueous $\mathrm{HCl}(0.65 \mathrm{~mL})$ at $0{ }^{\circ} \mathrm{C}$. After stirring for $1 \mathrm{~h}$ at $40^{\circ} \mathrm{C}$, the reaction was quenched by adding saturated aqueous $\mathrm{NaHCO}_{3}$. The mixture was extracted with EtOAc $(\times 3)$ and the combined organic layers were washed with brine, dried over $\mathrm{Na}_{2} \mathrm{SO}_{4}$, filtered, and concentrated under reduced pressure. The residue was purified with PTLC $($ EtOAc: $n$-hexane $=3: 7)$ to give methyl derivative 5 (5.2 mg, 68\%) as a yellow solid. m.p. $113^{\circ} \mathrm{C}$; $1 \mathrm{H}-\mathrm{NMR}\left(400 \mathrm{MHz}, \mathrm{CDCl}_{3}\right) \delta 10.89(1 \mathrm{H}, \mathrm{s}), 6.93(1 \mathrm{H}, \mathrm{s})$, $5.59(1 \mathrm{H}, \mathrm{br}-\mathrm{s}), 4.75(1 \mathrm{H}, \mathrm{d}, J=2.7 \mathrm{~Hz}), 4.48(1 \mathrm{H}, \mathrm{ddd}, J=2.7,5.4,8,3 \mathrm{~Hz}), 3.37(3 \mathrm{H}, \mathrm{s}), 2.25(3 \mathrm{H}, \mathrm{s}), 1.93$ $(1 \mathrm{H}, \mathrm{m}), 1.84(1 \mathrm{H}, \mathrm{m}), 1.70-1.50(1 \mathrm{H}$, overlapped $), 1.45(1 \mathrm{H}, \mathrm{m}), 1.40-1.25(4 \mathrm{H}$, overlapped $), 0.91(3 \mathrm{H}$, $\mathrm{t}, J=6.6 \mathrm{~Hz}) ; 13 \mathrm{C}-\mathrm{NMR}\left(125 \mathrm{MHz}, \mathrm{CDCl}_{3}\right) \delta 169.4,154.9,144.9,128.7,125.8,118.6,106.6,81.4,69.8$, 56.5, 31.6, 29.8, 24.9, 22.5, 15.8, 14.0.; IR (KBr) 3340, 2957, 2928, 2859, 1682, 1654, 1604, 1296, $1172 \mathrm{~cm}^{-1}$; HRMS (ESI) $m / z(\mathrm{M}+\mathrm{Na})^{+}$calculated for $\left(\mathrm{C}_{16} \mathrm{H}_{22} \mathrm{O}_{5} \mathrm{Na}\right)^{+}$317.1365, found 317.1350.

\subsection{6. (3S,4S)-4-methoxy-5,8-bis(methoxymethoxy)-3-pentyl-7-vinylisochroman-1-one (7a)}

To a solution of bromo compound $3(200 \mathrm{mg}, 0.447 \mathrm{mmol})$ and CsF (135.8 $\mathrm{mg}, 0.894 \mathrm{mmol})$ in degassed DMF $(2.2 \mathrm{~mL})$ were added tributylvinyltin $(0.26 \mathrm{~mL}, 0.894 \mathrm{mmol})$ and $\mathrm{PdCl}_{2}\left(\mathrm{PPh}_{3}\right)_{2}(62.8 \mathrm{mg}$, $89.0 \mu \mathrm{mol}$ ) at room temperature. After stirring for $1 \mathrm{~h}$ at $80^{\circ} \mathrm{C}$, the reaction was quenched by adding water. The mixture was extracted with EtOAc $(\times 3)$ and the combined organic layers were washed with brine, dried over $\mathrm{Na}_{2} \mathrm{SO}_{4}$, filtered, and concentrated under reduced pressure. The residue was purified with flash column chromatography (EtOAc: $n$-hexane $=3: 7)$ to give diMOM-protected vinyl derivative $7 \mathbf{a}\left(185.1 \mathrm{mg}\right.$, quant) as a yellow solid. m.p. $63-64{ }^{\circ} \mathrm{C} ; 1 \mathrm{H}-\mathrm{NMR}\left(500 \mathrm{MHz}, \mathrm{CDCl}_{3}\right) \delta 7.56$ $(1 \mathrm{H}, \mathrm{s}), 7.14(1 \mathrm{H}, \mathrm{dd}, J=11.1,17.7 \mathrm{~Hz}), 5.76(1 \mathrm{H}, \mathrm{d}, J=17.7 \mathrm{~Hz}), 5.40(1 \mathrm{H}, \mathrm{d}, J=11.1 \mathrm{~Hz}), 5.24(2 \mathrm{H}$, s), $5.08(1 \mathrm{H}, \mathrm{d}, J=6.3 \mathrm{~Hz}), 5.05(1 \mathrm{H}, \mathrm{d}, J=6.3 \mathrm{~Hz}), 4.60(1 \mathrm{H}, \mathrm{d}, J=1.3 \mathrm{~Hz}), 4.26(1 \mathrm{H}, \mathrm{ddd}, J=1.3,5.8$, $7.4 \mathrm{~Hz}), 3.58(3 \mathrm{H}, \mathrm{s}), 3.50(3 \mathrm{H}, \mathrm{s}), 3.31(3 \mathrm{H}, \mathrm{s}), 2.03(1 \mathrm{H}, \mathrm{m}), 1.81(1 \mathrm{H}, \mathrm{m}), 1.56(1 \mathrm{H}, \mathrm{m}), 1.43(1 \mathrm{H}, \mathrm{m})$, 1.40-1.25 (4H, overlapped), $0.90(3 \mathrm{H}, \mathrm{t}, J=6.9 \mathrm{~Hz}) ; 13 \mathrm{C}-\mathrm{NMR}\left(125 \mathrm{MHz}, \mathrm{CDCl}_{3}\right) \delta 162.0,150.7,150.2$, 134.9, 131.3, 128.5, 119.7, 116.7, 116.0, 101.5, 95.2, 80.8, 68.3, 57.9, 56.8, 56.4, 31.6, 30.6, 24.9, 22.5, 14.0.; IR (KBr) 2953, 2931, 2861, 2829, 1730, 1471, 1426, 1155, $929 \mathrm{~cm}^{-1}$; HRMS (ESI) $\mathrm{m} / \mathrm{z}(\mathrm{M}+\mathrm{H})^{+}$calculated for $\left(\mathrm{C}_{21} \mathrm{H}_{31} \mathrm{O}_{7}\right)^{+}$395.2070, found 395.2078.

\subsection{7. (3S,4S)-5,8-dihydroxy-4-methoxy-3-pentyl-7-vinylisochroman-1-one (7)}

To a solution of diMOM-protected methyl derivative $7 \mathbf{a}(13.7 \mathrm{mg}, 34.7 \mu \mathrm{mol})$ in $\mathrm{MeOH}(2.6 \mathrm{~mL})$ was added $6 \mathrm{M}$ aqueous $\mathrm{HCl}(0.87 \mathrm{~mL})$ at $0{ }^{\circ} \mathrm{C}$. After stirring for $3 \mathrm{~h}$ at $40{ }^{\circ} \mathrm{C}$, the reaction was quenched 
by adding saturated aqueous $\mathrm{NaHCO}_{3}$. The mixture was extracted with EtOAc $(\times 3)$ and the combined organic layers were washed with brine, dried over $\mathrm{Na}_{2} \mathrm{SO}_{4}$, filtered, and concentrated under reduced pressure. The residue was purified with PTLC (EtOAc: $n$-hexane $=3: 7$ ) to give vinyl derivative 7 $(8.5 \mathrm{mg}, 75 \%)$ as a yellow wax. 1H-NMR $\left(500 \mathrm{MHz}, \mathrm{CDCl}_{3}\right) \delta 11.10(1 \mathrm{H}, \mathrm{s}), 7.23(1 \mathrm{H}, \mathrm{s}), 7.01(1 \mathrm{H}, \mathrm{dd}$, $J=11.4,17.7 \mathrm{~Hz}), 5.82(1 \mathrm{H}, \mathrm{br}-\mathrm{s}), 5.80(1 \mathrm{H}, \mathrm{d}, J=18.0 \mathrm{~Hz}), 5.37(1 \mathrm{H}, \mathrm{d}, J=11.0 \mathrm{~Hz}), 4.77(1 \mathrm{H}, \mathrm{br}-\mathrm{s}), 4.50$ $(1 \mathrm{H}, \mathrm{br}-\mathrm{s}), 3.40(3 \mathrm{H}, \mathrm{s}), 1.95(1 \mathrm{H}, \mathrm{m}), 1.85(1 \mathrm{H}, \mathrm{m}), 1.58(1 \mathrm{H}, \mathrm{m}), 1.45(1 \mathrm{H}, \mathrm{m}), 1.40-1.25$ (4H, overlapped), 0.90 (3H, br-s); 13C-NMR (125 MHz, CDCl 3 ) $\delta 169.3,153.9,145.4,129.8,128.0,121.4,120.9,116.5,107.7$, 81.5, 69.7, 56.8, 31.6, 29.8, 24.9, 22.5, 14.0.; IR (KBr) 3311, 2956, 2930, 2859, 1659, 1438, $1171 \mathrm{~cm}^{-1}$; HRMS (ESI) $m / z(\mathrm{M}+\mathrm{Na})^{+}$calculated for $\left(\mathrm{C}_{17} \mathrm{H}_{22} \mathrm{O}_{5} \mathrm{Na}\right)^{+} 329.1365$, found 329.1368.

\subsection{8. (3S,4S)-4-methoxy-5,8-bis(methoxymethoxy)-3-pentyl-7-phenylisochroman-1-one (9a)}

Bromo compound $3(10.0 \mathrm{mg}, 22.4 \mu \mathrm{mol}), \mathrm{Cs}_{2} \mathrm{CO}_{3}(21.9 \mathrm{mg}, 67.1 \mu \mathrm{mol})$, phenylboronic acid $(5.5 \mathrm{mg}, 44.7 \mu \mathrm{M})$, and $\mathrm{PdCl}_{2}\left(\mathrm{PPh}_{3}\right)_{2}(3.1 \mathrm{mg}, 44.7 \mu \mathrm{mol})$ were dissolved in degassed dioxane $(0.22 \mathrm{~mL})$ at room temperature. After stirring for $1 \mathrm{~h}$ under reflux condition, the reaction was quenched by adding saturated aqueous $\mathrm{NH}_{4} \mathrm{Cl}$. The mixture was extracted with EtOAc $(\times 3)$ and the combined organic layers were washed with brine, dried over $\mathrm{Na}_{2} \mathrm{SO}_{4}$, filtered, and concentrated under reduced pressure. The residue was purified with flash column chromatography (EtOAc: $n$-hexane $=3: 7$ ) to give diMOM-protected phenyl derivative $9 \mathrm{a}(7.4 \mathrm{mg}, 75 \%)$ as a white wax. $1 \mathrm{H}-\mathrm{NMR}\left(500 \mathrm{MHz}, \mathrm{CDCl}_{3}\right) \delta$ $7.55(1 \mathrm{H}, \mathrm{d}, J=7.6 \mathrm{~Hz}), 7.50-7.38(3 \mathrm{H}$, overlapped), $7.36(1 \mathrm{H}, \mathrm{dd}, J=7.3 \mathrm{~Hz}), 5.25(2 \mathrm{H}, \mathrm{s}), 4.80(2 \mathrm{H}, \mathrm{s})$, $4.66(1 \mathrm{H}, \mathrm{s}), 4.33(1 \mathrm{H}, \mathrm{t}, J=7.0 \mathrm{~Hz}), 3.50(3 \mathrm{H}, \mathrm{s}), 3.37(3 \mathrm{H}, \mathrm{s}), 2.92(3 \mathrm{H}, \mathrm{s}), 2.06(1 \mathrm{H}, \mathrm{m}), 1.85(1 \mathrm{H}, \mathrm{m})$, 1.70-1.50 (1H, overlapped), 1.50-1.25 (5H, overlapped), 0.92 (3H, br-s); 13C-NMR (125 MHz, $\left.\mathrm{CDCl}_{3}\right) \delta$ 162.1, 150.5, 150.0, 139.5, 137.9, 129.8, 128.3, 128.1, 127.7, 121.0, 119.9, 101.0, 95.1, 80.8, 68.3, 57.1, 56.4, 31.6, 30.6, 24.9, 22.5, 14.0.; IR (KBr) 2956, 2927, 2859, 2828, 1728, 1467, 1152, 1008, $932 \mathrm{~cm}^{-1}$; HRMS (ESI) $m / z(\mathrm{M}+\mathrm{Na})^{+}$calculated for $\left(\mathrm{C}_{25} \mathrm{H}_{32} \mathrm{O}_{7} \mathrm{Na}\right)^{+} 467.2046$, found 467.2043.

\subsection{9. (3S,4S)-5,8-dihydroxy-4-methoxy-3-pentyl-7-phenylisochroman-1-one (9)}

To a solution of diMOM-protected methyl derivative $9 \mathrm{a}(7.4 \mathrm{mg}, 16.8 \mu \mathrm{mol})$ in THF $(1.0 \mathrm{~mL})$ was added $6 \mathrm{M}$ aqueous $\mathrm{HCl}(0.50 \mathrm{~mL})$ at $0{ }^{\circ} \mathrm{C}$. After stirring for $6 \mathrm{~h}$ at room temperature, the reaction was quenched by adding saturated aqueous $\mathrm{NaHCO}_{3}$. The mixture was extracted with EtOAc $(\times 3)$ and the combined organic layers were washed with brine, dried over $\mathrm{Na}_{2} \mathrm{SO}_{4}$, filtered, and concentrated under reduced pressure. The residue was purified with PTLC (EtOAc: $n$-hexane $=3: 7)$ to give phenyl derivative $9(6.0 \mathrm{mg}, 90 \%)$ as a yellow solid. m.p. $173-174{ }^{\circ} \mathrm{C}$; $1 \mathrm{H}-\mathrm{NMR}\left(400 \mathrm{MHz}, \mathrm{CDCl}_{3}\right) \delta 11.21$ $(1 \mathrm{H}, \mathrm{s}), 7.58(2 \mathrm{H}, \mathrm{d}, J=7.3 \mathrm{~Hz}), 7.44(2 \mathrm{H}, \mathrm{t}, J=7.3 \mathrm{~Hz}), 7.38(1 \mathrm{H}, \mathrm{d}, J=7.6 \mathrm{~Hz}), 7.13(1 \mathrm{H}, \mathrm{s}), 5.76(1 \mathrm{H}$, br-s), $4.82(1 \mathrm{H}, \mathrm{d}, J=2.7 \mathrm{~Hz}), 4.55(1 \mathrm{H}, \mathrm{ddd}, J=2.7,5.1,8.3 \mathrm{~Hz}), 3.44(3 \mathrm{H}, \mathrm{s}), 1.98(1 \mathrm{H}, \mathrm{m}), 1.89(1 \mathrm{H}, \mathrm{m})$, 1.70-1.40 (2H, overlapped), 1.40-1.25 (4H, overlapped), $0.92(3 \mathrm{H}, \mathrm{t}, J=6.8 \mathrm{~Hz}) ; 13 \mathrm{C}-\mathrm{NMR}(125 \mathrm{MHz}$, $\left.\mathrm{CDCl}_{3}\right) \delta 169.5,153.7,145.4,136.2,131.8,129.2,128.3,127.9,125.5,121.1,107.8,81.6,69.6,56.9,31.6,29.8$, 24.9, 22.5, 14.0.; IR (KBr) 3307, 2955, 2928, 2859, 1650, 1425, 1295, $1194 \mathrm{~cm}^{-1}$; HRMS (ESI) $\mathrm{m} / z(\mathrm{M}+\mathrm{H})^{+}$ calculated for $\left(\mathrm{C}_{21} \mathrm{H}_{25} \mathrm{O}_{5}\right)^{+} 357.1702$, found 357.1707.

3.1.10. (3S,4S)-7-([1,1'-biphenyl]-4-yl)-4-methoxy-5,8-bis(methoxymethoxy)-3-pentylisochroman-1one (10a)

Bromo compound $3(20.0 \mathrm{mg}, 44.7 \mu \mathrm{mol}), \mathrm{Cs}_{2} \mathrm{CO}_{3}(21.9 \mathrm{mg}, 67.1 \mu \mathrm{mol})$, 4-biphenylboronic acid ( $5.5 \mathrm{mg}, 44.7 \mu \mathrm{mol})$, and $\mathrm{PdCl}_{2}\left(\mathrm{PPh}_{3}\right)_{2}(3.2 \mathrm{mg}, 4.47 \mu \mathrm{mol})$ were dissolved in degassed dioxane $(0.23 \mathrm{~mL})$ at room temperature. After stirring for $1 \mathrm{~h}$ under reflux condition, the reaction was quenched by adding saturated aqueous $\mathrm{NH}_{4} \mathrm{Cl}$. The mixture was extracted with EtOAc $(\times 3)$ and the combined organic layers were washed with brine, dried over $\mathrm{Na}_{2} \mathrm{SO}_{4}$, filtered, and concentrated under reduced pressure. The residue was purified with PTLC (EtOAc: $n$-hexane $=3: 7$ ) to give diMOM-protected biphenyl derivative 10a $(18.0 \mathrm{mg}, 88 \%)$ as a white solid. $1 \mathrm{H}-\mathrm{NMR}\left(500 \mathrm{MHz}, \mathrm{CDCl}_{3}\right) \delta 7.74-7.60(6 \mathrm{H}$, overlapped), 7.53-7.40 (3H, overlapped), $7.38(1 \mathrm{H}, \mathrm{t}, J=7.3 \mathrm{~Hz}), 5.28(2 \mathrm{H}, \mathrm{s}), 4.85(1 \mathrm{H}, \mathrm{d}, J=7.0 \mathrm{~Hz})$, $4.84(1 \mathrm{H}, \mathrm{d}, J=7.0 \mathrm{~Hz}), 4.68(1 \mathrm{H}, \mathrm{d}, J=1.3 \mathrm{~Hz}), 4.35(1 \mathrm{H}, \mathrm{ddd}, J=1.3,6.0,7.6 \mathrm{~Hz}), 3.51(3 \mathrm{H}, \mathrm{s}), 3.38$ 
(3H, s), 2.99 (3H, s), $2.08(1 \mathrm{H}, \mathrm{m}), 1.86(1 \mathrm{H}, \mathrm{m}), 1.70-1.50(1 \mathrm{H}$, overlapped), $1.46(1 \mathrm{H}, \mathrm{m}), 1.40-1.25(4 \mathrm{H}$, overlapped), $0.92(3 \mathrm{H}, \mathrm{t}, J=6.9 \mathrm{~Hz}) ; 13 \mathrm{C}-\mathrm{NMR}\left(125 \mathrm{MHz}, \mathrm{CDCl}_{3}\right) \delta 162.1,150.6,150.0,140.5,140.4$, 139.1, 136.8, 130.2, 128.9, 128.1, 127.5, 127.0, 126.9, 120.9, 120.0, 101.1, 95.1, 80.8, 68.3, 57.2, 56.9, 56.4, 31.6, 30.6, 24.9, 22.5, 14.0.; IR (KBr) 2956, 2927, 2858, 2827, 1728, 1467, 1152, 1007, $931 \mathrm{~cm}^{-1}$; HRMS (ESI) $m / z(\mathrm{M}+\mathrm{H})^{+}$calculated for $\left(\mathrm{C}_{31} \mathrm{H}_{37} \mathrm{O}_{7}\right)^{+} 521.2539$, found 521.2539.

\subsubsection{1. (3S,4S)-7-([1,1'-biphenyl]-4-yl)-5,8-dihydroxy-4-methoxy-3-pentylisochroman-1-one (10)}

To a solution of diMOM-protected biphenyl derivative $10 \mathrm{a}(12.9 \mathrm{mg}, 24.8 \mu \mathrm{mol})$ in THF $(1.7 \mathrm{~mL})$ was added $6 \mathrm{M}$ aqueous $\mathrm{HCl}(0.83 \mathrm{~mL})$ at $0{ }^{\circ} \mathrm{C}$. After stirring for $17 \mathrm{~h}$ at room temperature, the reaction was quenched by adding saturated aqueous $\mathrm{NaHCO}_{3}$ at $0{ }^{\circ} \mathrm{C}$. The mixture was extracted with EtOAc $(\times 3)$ and the combined organic layers were washed with brine, dried over $\mathrm{Na}_{2} \mathrm{SO}_{4}$, filtered, and concentrated under reduced pressure. The residue was purified with PTLC (EtOAc: $n$-hexane $=3: 7)$ to give biphenyl derivative $10(9.9 \mathrm{mg}, 92 \%)$ as a yellow solid. m.p. $181-182{ }^{\circ} \mathrm{C} ; 1 \mathrm{H}-\mathrm{NMR}(400 \mathrm{MHz}$, $\left.\mathrm{CDCl}_{3}\right) \delta 11.28(1 \mathrm{H}, \mathrm{s}), 7.67(4 \mathrm{H}, \mathrm{s}), 7.64(2 \mathrm{H}, \mathrm{d}, J=7.3 \mathrm{~Hz}), 7.46(2 \mathrm{H}, \mathrm{t}, J=7.3 \mathrm{~Hz}), 7.37(1 \mathrm{H}, \mathrm{t}, J=7.3$ $\mathrm{Hz}), 7.19(1 \mathrm{H}, \mathrm{s}), 5.75(1 \mathrm{H}, \mathrm{br}-\mathrm{s}), 4.84(1 \mathrm{H}, \mathrm{d}, J=2.7 \mathrm{~Hz}), 4.56(1 \mathrm{H}, \mathrm{ddd}, J=2.7,5.4,8.3 \mathrm{~Hz}), 3.46(3 \mathrm{H}, \mathrm{s})$, $1.98(1 \mathrm{H}, \mathrm{m}), 1.89(1 \mathrm{H}, \mathrm{m}), 1.70-1.50$ (2H, overlapped), 1.45-1.25 (4H, overlapped), $0.92(3 \mathrm{H}, \mathrm{t}, J=6.8$ $\mathrm{Hz})$; 13C-NMR $\left(125 \mathrm{MHz}, \mathrm{CDCl}_{3}\right) \delta$ 169.4, 153.8, 145.5, 140.7, 135.2, 131.4, 129.6, 128.8, 127.5,127.15, 127.07, 125.3, 121.0, 107.9, 81.5, 69.8, 56.9, 31.6, 29.8, 24.9, 22.5, 14.0.; IR (KBr) 3283, 2954, 2929, 2863, $1668,1595,1295,1220,772 \mathrm{~cm}^{-1}$; HRMS (ESI) $\mathrm{m} / z(\mathrm{M}+\mathrm{Na})^{+}$calculated for $\left(\mathrm{C}_{27} \mathrm{H}_{28} \mathrm{O}_{5} \mathrm{Na}\right)^{+} 455.1834$, found 455.1831 .

\subsubsection{2. (3S,4S)-7-ethynyl-4-methoxy-5,8-bis(methoxymethoxy)-3-pentylisochroman-1-one (8a)}

To a solution of aldehyde $12 \mathrm{a}(5.4 \mathrm{mg}, 13.6 \mu \mathrm{mol})$ in $\mathrm{MeOH}(0.14 \mathrm{~mL})$ were added $\mathrm{K}_{2} \mathrm{CO}_{3}(5.7 \mathrm{mg}$, $40.9 \mu \mathrm{mol})$ and Ohira-Bestmann reagent $(3.9 \mathrm{mg}, 20.4 \mu \mathrm{mol})$ at room temperature. After stirring for $40 \mathrm{~min}$ at the same temperature, the mixture was concentrated under reduced pressure. The residue was purified with column chromatography (EtOAc: $n$-hexane $=1: 4$ to 1:1) to give diMOM alkyne derivative $8 \mathbf{a}\left(6.3 \mathrm{mg}\right.$, quant) as a yellow oil. $1 \mathrm{H}-\mathrm{NMR}\left(500 \mathrm{MHz}, \mathrm{CDCl}_{3}\right) \delta 7.52(1 \mathrm{H}, \mathrm{s}), 5.27(1 \mathrm{H}, \mathrm{d}$, $J=6.0 \mathrm{~Hz}), 5.22(2 \mathrm{H}, \mathrm{s}), 5.17(1 \mathrm{H}, \mathrm{d}, J=6.0 \mathrm{~Hz}), 4.59(1 \mathrm{H}, \mathrm{d}, J=1.3 \mathrm{~Hz}), 4.27(1 \mathrm{H}, \mathrm{ddd}, J=1.3,5.8$, $7.4 \mathrm{~Hz}), 3.65(3 \mathrm{H}, \mathrm{s}), 3.49(3 \mathrm{H}, \mathrm{s}), 3.32(3 \mathrm{H}, \mathrm{s}), 2.05(1 \mathrm{H}, \mathrm{m}), 1.82(1 \mathrm{H}, \mathrm{m}), 1.65-1.50(1 \mathrm{H}$, overlapped), $1.42(1 \mathrm{H}, \mathrm{m}), 1.40-1.25$ (4H, overlapped), $0.91(3 \mathrm{H}, \mathrm{t}, J=7.1 \mathrm{~Hz}) ; 13 \mathrm{C}-\mathrm{NMR}\left(125 \mathrm{MHz}, \mathrm{CDCl}_{3}\right) \delta 161.2$, 154.6, 149.5, 130.0, 123.5, 120.4, 120.1, 101.0, 95.2, 82.7, 80.7, 79.3, 68.3, 58.1, 57.0, 56.5, 31.6, 30.5, 24.8, 22.5, 14.0.; IR (KBr) 3260, 2954, 2932, 2861, 2830, 1730, 1155, 1012, $931 \mathrm{~cm}^{-1}$; HRMS (ESI) $m / z(\mathrm{M}+\mathrm{H})^{+}$ calculated for $\left(\mathrm{C}_{21} \mathrm{H}_{29} \mathrm{O}_{7}\right)^{+} 393.1913$, found 393.1903 .

\subsubsection{3. (3S,4S)-7-ethynyl-5,8-dihydroxy-4-methoxy-3-pentylisochroman-1-one (8)}

To a solution of diMOM alkyne derivative $8 \mathrm{a}(6.3 \mathrm{mg}, 13.6 \mu \mathrm{mol})$ in $\mathrm{MeOH}(1.2 \mathrm{~mL})$ was added $6 \mathrm{M}$ aqueous $\mathrm{HCl}(0.40 \mathrm{~mL})$ at room temperature. After stirring for $24 \mathrm{~h}$ at the same temperature, the reaction was quenched by adding saturated aqueous $\mathrm{NaHCO}_{3}$ at $0{ }^{\circ} \mathrm{C}$. The mixture was extracted with EtOAc (×3) and the combined organic layers were washed with brine, dried over $\mathrm{Na}_{2} \mathrm{SO}_{4}$, filtered, and concentrated under reduced pressure. The residue was purified with column chromatography (EtOAc: $n$-hexane $=1: 4$ to 1:1) to give alkyne derivative $8(3.3 \mathrm{mg}, 67 \%$ ) as a yellow solid. m.p. 132-133 ${ }^{\circ} \mathrm{C}$; $1 \mathrm{H}-\mathrm{NMR}\left(500 \mathrm{MHz}, \mathrm{CDCl}_{3}\right) \delta 11.20(1 \mathrm{H}, \mathrm{s}), 7.22(1 \mathrm{H}, \mathrm{s}), 6.03(1 \mathrm{H}, \mathrm{br}-\mathrm{s}), 4.76(1 \mathrm{H}, \mathrm{d}$, $J=2.5 \mathrm{~Hz}), 4.51(1 \mathrm{H}, \mathrm{ddd}, J=2.5,5.1,8.2 \mathrm{~Hz}), 3.40(3 \mathrm{H}, \mathrm{s}), 3.39(1 \mathrm{H}, \mathrm{s}), 1.94(1 \mathrm{H}, \mathrm{m}), 1.84(1 \mathrm{H}, \mathrm{m})$, 1.70-1.50 (1H, overlapped), $1.45(1 \mathrm{H}, \mathrm{m}), 1.40-1.25$ (4H, overlapped), $0.91(3 \mathrm{H}, \mathrm{t}, J=7.0 \mathrm{~Hz}) ; 13 \mathrm{C}-\mathrm{NMR}$ $\left(125 \mathrm{MHz}_{,} \mathrm{CDCl}_{3}\right) \delta 168.6,157.3,145.1,127.8,123.4,112.6,108.0,83.2,81.4,77.7,69.7,57.0,31.5,29.7$, 24.8, 22.5, 14.0.; IR (KBr) 3294, 2956, 2930, 2859, 1679, 1434, $1172 \mathrm{~cm}^{-1}$; HRMS (ESI) $m / z(\mathrm{M}+\mathrm{H})^{+}$ calculated for $\left(\mathrm{C}_{17} \mathrm{H}_{21} \mathrm{O}_{5}\right)^{+} 305.1389$, found 305.1391 . 
3.1.14. (3S,4S)-4-methoxy-5,8-bis(methoxymethoxy)-1-oxo-3-pentylisochromane-7-carbaldehyde (12a)

A stirred solution of $7 \mathrm{a}(185.1 \mathrm{mg}, 0.469 \mathrm{mmol})$ in $\mathrm{CH}_{2} \mathrm{Cl}_{2}(10.0 \mathrm{~mL})$ was cooled to $-78^{\circ} \mathrm{C}$ and a stream of ozone was passed through it for $30 \mathrm{~min}$. At this time, ozone gas was bubbled into the reaction mixture until the color of the reaction mixture turned to blue. After completion of the reaction, the mixture was purged with oxygen gas for $30 \mathrm{~min}$ before being treated with $\mathrm{PPh}_{3}(246.2 \mathrm{mg}, 0.939$ $\mathrm{mmol}$ ) and allowed to warm to room temperature. After stirring at the same temperature for $12 \mathrm{~h}$, the mixture was concentrated under reduced pressure and the resultant mixture was purified with column chromatography (EtOAc: $n$-hexane $=1: 4$ to $2: 3)$ to give diMOM benzaldehyde derivative 12a $(177.4 \mathrm{mg}$, $95 \%)$ as a white solid. m.p. $38-39^{\circ} \mathrm{C}$; $1 \mathrm{H}-\mathrm{NMR}\left(400 \mathrm{MHz}, \mathrm{CDCl}_{3}\right) \delta 10.42(1 \mathrm{H}, \mathrm{s}), 7.83(1 \mathrm{H}, \mathrm{s}), 5.29(2 \mathrm{H}$, s), $5.2(2 \mathrm{H}, \mathrm{s}), 4.65(1 \mathrm{H}, \mathrm{d}, J=1.0 \mathrm{~Hz}), 4.29(1 \mathrm{H}, J=1.0,5.6,8.3 \mathrm{~Hz}), 3.59(3 \mathrm{H}, \mathrm{s}), 3.50(3 \mathrm{H}, \mathrm{s}), 3.35(3 \mathrm{H}, \mathrm{s})$, $2.06(1 \mathrm{H}, \mathrm{m}), 1.83(1 \mathrm{H}, \mathrm{m}), 1.70-1.50(1 \mathrm{H}$, overlapped $), 1.44(1 \mathrm{H}, \mathrm{m}), 1.40-1.30(4 \mathrm{H}$, overlapped), $0.91(3 \mathrm{H}$, $\mathrm{t}, J=7.1 \mathrm{~Hz}) ; 13 \mathrm{C}-\mathrm{NMR}\left(125 \mathrm{MHz}, \mathrm{CDCl}_{3}\right) \delta 189.9,161.4,156.6,150.6,135.8,132.5,120.8,116.9,103.0$, 95.4, 81.0, 68.7, 58.4, 57.8, 57.0, 31.9, 30.8, 25.2, 22.8, 14.3.; IR (KBr) 2957, 2929, 2859, 2829, 1730, 1691, $1379,1155,930 \mathrm{~cm}^{-1}$; HRMS (ESI) $\mathrm{m} / z(\mathrm{M}+\mathrm{H})^{+}$calculated for $\left(\mathrm{C}_{20} \mathrm{H}_{29} \mathrm{O}_{8}\right)^{+} 397.1862$, found 397.1866.

\subsubsection{5. (3S,4S)-5,8-dihydroxy-4-methoxy-1-oxo-3-pentylisochromane-7-carbaldehyde (12)}

To a solution of diMOM aldehyde derivative $12 \mathrm{a}(10.0 \mathrm{mg}, 25.2 \mu \mathrm{mol})$ in THF $(1.9 \mathrm{~mL})$ was added 6 $\mathrm{M}$ aqueous $\mathrm{HCl}(0.63 \mathrm{~mL})$ at $0{ }^{\circ} \mathrm{C}$. After stirring for $4 \mathrm{~h}$ at room temperature, the reaction was quenched by adding saturated aqueous $\mathrm{NaHCO}_{3}$ at $0^{\circ} \mathrm{C}$. The mixture was extracted with EtOAc $(\times 3)$ and the combined organic layers were washed with brine, dried over $\mathrm{Na}_{2} \mathrm{SO}_{4}$, filtered, and concentrated under reduced pressure. The residue was purified with PTLC (EtOAc: $n$-hexane $=2: 3$ ) to give benzaldehyde derivative $12(6.0 \mathrm{mg}, 77 \%)$ as a pale yellow solid. m.p. $170{ }^{\circ} \mathrm{C}(\mathrm{dec}) ; 1 \mathrm{H}-\mathrm{NMR}\left(400 \mathrm{MHz}, \mathrm{CDCl}_{3}\right) \delta$ $11.33(1 \mathrm{H}, \mathrm{s}), 10.47(1 \mathrm{H}, \mathrm{s}), 7.70(1 \mathrm{H}, \mathrm{d}, J=1.5 \mathrm{~Hz}), 6.62(1 \mathrm{H}, \mathrm{br}-\mathrm{s}), 4.75(1 \mathrm{H}, \mathrm{d}, J=2.2 \mathrm{~Hz}), 4.49(1 \mathrm{H}, \mathrm{ddd}$, $J=2.2,5.6,8.0 \mathrm{~Hz}), 3.43(3 \mathrm{H}, \mathrm{s}), 2.03(1 \mathrm{H}, \mathrm{s}), 1.88(1 \mathrm{H}, \mathrm{m}), 1.61(1 \mathrm{H}, \mathrm{m}), 1.48(1 \mathrm{H}, \mathrm{m}), 1.42-1.30(4 \mathrm{H}$, overlapped), $0.92(3 \mathrm{H}, \mathrm{t}, J=6.8 \mathrm{~Hz}) ; 13 \mathrm{C}-\mathrm{NMR}\left(125 \mathrm{MHz}, \mathrm{CDCl}_{3}\right) \delta 189.0,168.8,158.9,146.0,131.3$, 124.9, 121.5, 110.2, 82.2, 69.2, 57.9, 31.9, 30.3, 25.1, 22.8, 14.3.; IR (KBr) 3444, 3169, 2953, 2940, 2920, 1676, $1455,1395,1299 \mathrm{~cm}^{-1}$; HRMS (ESI) $\mathrm{m} / z(\mathrm{M}+\mathrm{H})^{+}$calculated for $\left(\mathrm{C}_{16} \mathrm{H}_{21} \mathrm{O}_{6}\right)^{+} 309.1338$, found 309.1342.

3.1.16. (3S,4S)-7-(hydroxymethyl)-4-methoxy-5,8-bis(methoxymethoxy)-3-pentylisochroman-1one (11a)

To a solution of diMOM aldehyde derivative 12a $(20.0 \mathrm{mg}, 50.5 \mu \mathrm{mol})$ in $\mathrm{MeOH}(0.25 \mathrm{~mL})$ was added $\mathrm{NaBH}_{4}(2.1 \mathrm{mg}, 55.5 \mu \mathrm{mol})$ at $0{ }^{\circ} \mathrm{C}$. After stirring for $15 \mathrm{~min}$ at the same temperature, the reaction was quenched by adding water at $0{ }^{\circ} \mathrm{C}$. The mixture was extracted with EtOAc $(\times 3)$ and the combined organic layers were washed with brine, dried over $\mathrm{Na}_{2} \mathrm{SO}_{4}$, filtered, and concentrated under reduced pressure. The residue was purified with PTLC (EtOAc: $n$-hexane $=1: 1)$ to give diMOM hydroxymethyl derivative 11a $(18.6 \mathrm{mg}, 93 \%)$ as a white wax. $1 \mathrm{H}-\mathrm{NMR}\left(400 \mathrm{MHz}, \mathrm{CDCl}_{3}\right) \delta 7.46(1 \mathrm{H}, \mathrm{s}), 5.25(1 \mathrm{H}, \mathrm{d}$, $J=6.8 \mathrm{~Hz}), 5.24(1 \mathrm{H}, \mathrm{d}, J=6.8 \mathrm{~Hz}), 5.15(2 \mathrm{H}, \mathrm{s}), 4.72(1 \mathrm{H}, \mathrm{dd}, J=6.4,12.5 \mathrm{~Hz}), 4.62(1 \mathrm{H}, \mathrm{d}, J=1.2 \mathrm{~Hz})$, $4.58(1 \mathrm{H}, \mathrm{dd}, J=7.8,12.5 \mathrm{~Hz}), 4.25(1 \mathrm{H}, \mathrm{ddd}, J=1.2,5.8,8.0 \mathrm{~Hz}), 3.64(3 \mathrm{H}, \mathrm{s}), 3.55(1 \mathrm{H}, \mathrm{t}, J=6.8 \mathrm{~Hz})$, $3.50(3 \mathrm{H}, \mathrm{s}), 3.31(3 \mathrm{H}, \mathrm{s}), 2.05(1 \mathrm{H}, \mathrm{m}), 1.83(1 \mathrm{H}, \mathrm{m}), 1.65-1.50(1 \mathrm{H}$, overlapped $), 1.43(1 \mathrm{H}, \mathrm{m}), 1.42-1.30$ (4H, overlapped), $0.91(3 \mathrm{H}, \mathrm{t}, J=6.8 \mathrm{~Hz})$; 13C-NMR $\left(125 \mathrm{MHz}, \mathrm{CDCl}_{3}\right) \delta 162.4,152.7,150.7,138.7,128.9$, $120.8,119.3,102.2,95.4,81.2,68.4,61.4,57.8,57.2,56.8,31.9,30.9,25.2,22.9,14.4 . ; \mathrm{IR}(\mathrm{KBr}) 3443,2957$, $2928,2859,2828,1724,1153,1012 \mathrm{~cm}^{-1}$; HRMS (ESI) $\mathrm{m} / z(\mathrm{M}+\mathrm{H})^{+}$calculated for $\left(\mathrm{C}_{20} \mathrm{H}_{31} \mathrm{O}_{8}\right)+399.2019$, found 399.2017 .

\subsubsection{7. (3S,4S)-5,8-dihydroxy-7-(hydroxymethyl)-4-methoxy-3-pentylisochroman-1-one (11)}

To a solution of diMOM hydroxymethyl derivative 11a $(7.2 \mathrm{mg}, 24.1 \mu \mathrm{mol})$ in $\mathrm{MeOH}(1.8 \mathrm{~mL})$ was added $6 \mathrm{M}$ aqueous $\mathrm{HCl}(0.45 \mathrm{~mL})$ at $0{ }^{\circ} \mathrm{C}$. After stirring for $4 \mathrm{~h}$ at $40{ }^{\circ} \mathrm{C}$, the reaction was quenched by adding saturated aqueous $\mathrm{NaHCO}_{3}$ at $0{ }^{\circ} \mathrm{C}$. The mixture was extracted with EtOAc $(\times 3)$ and the combined organic layers were washed with brine, dried over $\mathrm{Na}_{2} \mathrm{SO}_{4}$, filtered, and concentrated under 
reduced pressure. The residue was purified with PTLC (EtOAc: $n$-hexane $=1: 1$ ) to give hydroxymethyl derivative 11 (3.9 mg, 52\%) as a white solid. m.p. $143-145^{\circ} \mathrm{C}$; $1 \mathrm{H}-\mathrm{NMR}\left(400 \mathrm{MHz}, \mathrm{CDCl}_{3}\right) \delta 10.99$ $(1 \mathrm{H}, \mathrm{s}), 7.12(1 \mathrm{H}, \mathrm{s}), 6.03(1 \mathrm{H}, \mathrm{br}-\mathrm{s}), 4.74(1 \mathrm{H}, \mathrm{d}, J=2.4 \mathrm{~Hz}), 4.72(2 \mathrm{H}, \mathrm{br}-\mathrm{s}), 4.48(1 \mathrm{H}, \mathrm{ddd}, J=2.4,5.2$, $8.0 \mathrm{~Hz}), 3.38(3 \mathrm{H}, \mathrm{s}), 2.53(1 \mathrm{H}, \mathrm{br}-\mathrm{s}), 1.96(1 \mathrm{H}, \mathrm{m}), 1.86(1 \mathrm{H}, \mathrm{m}), 1.70-1.50(1 \mathrm{H}$, overlapped), $1.46(1 \mathrm{H}, \mathrm{m})$, 1.40-1.25 (4H, overlapped), $0.91(3 \mathrm{H}, \mathrm{t}, J=6.8 \mathrm{~Hz}) ; 13 \mathrm{C}-\mathrm{NMR}\left(125 \mathrm{MHz}, \mathrm{CDCl}_{3}\right) \delta 169.5,154.2,145.8$, 130.8, 123.8, 121.4, 107.8, 82.1, 69.8, 61.2, 57.2, 31.9, 30.2, 25.2, 22.8, 14.3.; IR (KBr) 2951, 2921, 2854, 1682, $1440,1302 \mathrm{~cm}^{-1}$; HRMS (ESI) $\mathrm{m} / z(\mathrm{M}+\mathrm{H})^{+}$calculated for $\left(\mathrm{C}_{16} \mathrm{H}_{23} \mathrm{O}_{6}\right)^{+} 311.1495$, found 311.1498.

3.1.18. ((3S,4S)-4-methoxy-5,8-bis(methoxymethoxy)-1-oxo-3-pentylisochroman-7-yl) methylmethanesulfonate (22)

To a solution of diMOM hydroxymethyl derivative 11a $(7.2 \mathrm{mg}, 24.1 \mu \mathrm{mol})$ in $\mathrm{CH}_{2} \mathrm{Cl}_{2}(0.47 \mathrm{~mL})$ were added $\mathrm{Et}_{3} \mathrm{~N}(10.8 \mu \mathrm{L}, 77.5 \mu \mathrm{mol})$ and $\mathrm{MsCl}(6.0 \mu \mathrm{L}, 77.5 \mu \mathrm{mol})$ at $0{ }^{\circ} \mathrm{C}$. After stirring for $40 \mathrm{~min}$ at the same temperature, the reaction was quenched by adding water at $0{ }^{\circ} \mathrm{C}$. The mixture was extracted with EtOAc $(\times 3)$ and the combined organic layers were washed with brine, dried over $\mathrm{Na}_{2} \mathrm{SO}_{4}$, filtered, and concentrated under reduced pressure. The residue was purified with PTLC (EtOAc: $n$-hexane $=2: 3)$ to give diMOM mesylated derivative $22(30.4 \mathrm{mg}, 91 \%)$ as a white wax. 1H-NMR $(400 \mathrm{MHz}$, $\left.\mathrm{CDCl}_{3}\right) \delta 7.51(1 \mathrm{H}, \mathrm{s}), 5.45(1 \mathrm{H}, \mathrm{d}, J=12.0 \mathrm{~Hz}), 5.37(1 \mathrm{H}, \mathrm{d}, J=12.2 \mathrm{~Hz}), 5.25(2 \mathrm{H}, \mathrm{s}), 5.14(1 \mathrm{H}, \mathrm{d}$, $J=6.6 \mathrm{~Hz}), 5.12(1 \mathrm{H}, \mathrm{d}, J=6.6 \mathrm{~Hz}), 4.62(1 \mathrm{H}, \mathrm{d}, J=1.4 \mathrm{~Hz}), 4.27(1 \mathrm{H}, \mathrm{ddd}, J=1.2,5.6,7.8 \mathrm{~Hz}), 3.59$ $(3 \mathrm{H}, \mathrm{s}), 3.50(3 \mathrm{H}, \mathrm{s}), 3.33(3 \mathrm{H}, \mathrm{s}), 3.07(3 \mathrm{H}, \mathrm{s}), 2.03(1 \mathrm{H}, \mathrm{m}), 1.82(1 \mathrm{H}, \mathrm{m}), 1.58(1 \mathrm{H}, \mathrm{m}), 1.44(1 \mathrm{H}, \mathrm{m})$, $1.40-1.25$ (4H, overlapped), $0.91(3 \mathrm{H}, \mathrm{t}, J=6.8 \mathrm{~Hz}) ; 13 \mathrm{C}-\mathrm{NMR}\left(100 \mathrm{MHz}, \mathrm{CDCl}_{3}\right) \delta 161.9,152.2,150.5$, 131.3, 130.5, 120.3, 119.7, 102.8, 95.5, 81.2, 68.6, 66.9, 58.1, 57.4, 56.9, 38.2, 31.9, 30.9, 25.2, 22.8, 14.3.; IR (KBr) 2958, 2930, 2860, 1829, 1681, 1440, 1358, 1175, $933 \mathrm{~cm}^{-1}$; HRMS (ESI) $m / z(\mathrm{M}+\mathrm{Na})^{+}$calculated for $\left(\mathrm{C}_{21} \mathrm{H}_{32} \mathrm{O}_{10} \mathrm{SNa}\right)^{+}$499.1614, found 499.1616 .

\subsubsection{9. (3S,4S)-7-(azidomethyl)-4-methoxy-5,8-bis(methoxymethoxy)-3-pentylisochroman-1-one (13a)}

To a solution of diMOM mesylated derivative $22(5.3 \mathrm{mg}, 11.1 \mu \mathrm{mol})$ in DMF $(55 \mu \mathrm{L})$ was added $\mathrm{NaN}_{3}(0.79 \mathrm{mg}, 12.1 \mu \mathrm{mol})$ at room temperature. After stirring for $6 \mathrm{~h}$ at the same temperature, the reaction was quenched by adding water at $0{ }^{\circ} \mathrm{C}$. The mixture was extracted with EtOAc $(\times 3)$ and the combined organic layers were washed with brine, dried over $\mathrm{Na}_{2} \mathrm{SO}_{4}$, filtered, and concentrated under reduced pressure. The residue was purified with PTLC (EtOAc: $n$-hexane $=3: 7$ ) to give diMOM azide derivative 13a $(3.7 \mathrm{mg}, 79 \%)$ as a pale-yellow oil. 1H-NMR $\left(500 \mathrm{MHz}, \mathrm{CDCl}_{3}\right) \delta 7.44(1 \mathrm{H}, \mathrm{s}), 5.26(1 \mathrm{H}, \mathrm{d}$, $J=6.9 \mathrm{~Hz}), 5.25(1 \mathrm{H}, \mathrm{d}, J=6.9 \mathrm{~Hz}), 5.13(1 \mathrm{H}, \mathrm{d}, J=6.9 \mathrm{~Hz}), 5.11(1 \mathrm{H}, \mathrm{d}, J=6.9 \mathrm{~Hz}), 4.65(1 \mathrm{H}, \mathrm{d}, J=14.5$ $\mathrm{Hz}), 4.62(1 \mathrm{H}, \mathrm{d}, J=1.3 \mathrm{~Hz}), 4.53(1 \mathrm{H}, \mathrm{d}, J=14.5 \mathrm{~Hz}), 4.27(1 \mathrm{H}, \mathrm{ddd}, J=1.3,5.7,7.3 \mathrm{~Hz}), 3.60(3 \mathrm{H}, \mathrm{s})$, $3.51(3 \mathrm{H}, \mathrm{s}), 3.32(3 \mathrm{H}, \mathrm{s}), 2.04(1 \mathrm{H}, \mathrm{m}), 1.82(1 \mathrm{H}, \mathrm{m}), 1.65-1.50(1 \mathrm{H}$, overlapped $), 1.43(1 \mathrm{H}, \mathrm{m}), 1.40-1.30$ (4H, overlapped), $0.91(3 \mathrm{H}, \mathrm{t}, J=7.0 \mathrm{~Hz}) ; 13 \mathrm{C}-\mathrm{NMR}\left(125 \mathrm{MHz}, \mathrm{CDCl}_{3}\right) \delta 162.2,152.1,150.5,133.5$, 129.1, 119.7, 119.5, 102.6, 95.5, 81.2, 68.6, 57.9, 57.3, 56.8, 50.2, 31.9, 30.9, 25.2, 22.9, 14.4.; IR (KBr) 2957, $2928,2858,2829,2105,1729,1153,1009 \mathrm{~cm}^{-1}$; HRMS (ESI) $\mathrm{m} / \mathrm{z}(\mathrm{M}+\mathrm{H})^{+}$calculated for $\left(\mathrm{C}_{20} \mathrm{H}_{30} \mathrm{~N}_{3} \mathrm{O}_{7}\right)^{+}$ 424.2084, found 424.2085 .

\subsubsection{0. (3S,4S)-7-(azidomethyl)-5,8-dihydroxy-4-methoxy-3-pentylisochroman-1-one (13)}

To a solution of diMOM azide derivative $13 \mathbf{a}(8.3 \mathrm{mg}, 19.6 \mu \mathrm{mol})$ in $\mathrm{MeOH}(1.5 \mathrm{~mL})$ was added $6 \mathrm{M}$ aqueous $\mathrm{HCl}(0.49 \mathrm{~mL})$ at room temperature. After stirring for $4 \mathrm{~h}$ at $40^{\circ} \mathrm{C}$, the reaction was quenched by adding saturated aqueous $\mathrm{NaHCO}_{3}$ at $0{ }^{\circ} \mathrm{C}$. The mixture was extracted with EtOAc $(\times 3)$ and the combined organic layers were washed with brine, dried over $\mathrm{Na}_{2} \mathrm{SO}_{4}$, filtered, and concentrated under reduced pressure. The residue was purified with PTLC (EtOAc: $n$-hexane $=3: 7$ ) to give nitro derivative $13(3.1 \mathrm{mg}, 49 \%)$ as a white solid. m.p. $98-99{ }^{\circ} \mathrm{C}$; $1 \mathrm{H}-\mathrm{NMR}\left(400 \mathrm{MHz}, \mathrm{CDCl}_{3}\right) \delta 10.98(1 \mathrm{H}, \mathrm{s}), 7.10(1 \mathrm{H}$, s), $5.81(1 \mathrm{H}, \mathrm{br}-\mathrm{s}), 4.78(1 \mathrm{H}, \mathrm{d}, J=2.9 \mathrm{~Hz}), 4.52(1 \mathrm{H}, \mathrm{ddd}, J=2.9,5.4,8.5 \mathrm{~Hz}), 4.45(1 \mathrm{H}, \mathrm{d}, J=14.4 \mathrm{~Hz})$, $4.42(1 \mathrm{H}, \mathrm{d}, J=14.4 \mathrm{~Hz}), 3.41(3 \mathrm{H}, \mathrm{s}), 1.93(1 \mathrm{H}, \mathrm{m}), 1.86(1 \mathrm{H}, \mathrm{m}), 1.70-1.50(1 \mathrm{H}$, overlapped $), 1.47(1 \mathrm{H}$, m), 1.40-1.25 (4H, overlapped), $0.91(3 \mathrm{H}, \mathrm{t}, J=7.1 \mathrm{~Hz}) ; 13 \mathrm{C}-\mathrm{NMR}\left(125 \mathrm{MHz}, \mathrm{CDCl}_{3}\right) \delta 169.1,154.4$, 145.7, 126.2, 124.6, 121.8, 108.0, 81.7, 70.4, 57.2, 49.3, 31.9, 30.0, 25.2, 22.8, 14.3.; IR (KBr) 2959, 2924, 2857, 
2108, 1654, 1441, 1293, $1170 \mathrm{~cm}^{-1}$; HRMS (ESI) $\mathrm{m} / \mathrm{z}(\mathrm{M}+\mathrm{H})^{+}$calculated for $\left(\mathrm{C}_{16} \mathrm{H}_{22} \mathrm{~N}_{3} \mathrm{O}_{5}\right)^{+} 336.1559$, found 336.1563 .

\subsubsection{1. (3S,4S)-7-(aminomethyl)-4-methoxy-5,8-bis(methoxymethoxy)-3-pentylisochroman-1-one (14a)}

To a solution of diMOM azide derivative $13 \mathrm{a}(3.3 \mathrm{mg}, 7.8 \mu \mathrm{mol})$ in $\mathrm{MeOH}(0.78 \mathrm{~mL})$ was added $\mathrm{Et}_{3} \mathrm{~N}(0.10 \mathrm{~mL}, 7.35 \mathrm{mmol})$ and $\mathrm{Pd} / \mathrm{C}(1.6 \mathrm{mg}, 1.5 \mu \mathrm{mol})$ at room temperature. After stirring for $1 \mathrm{~h}$ at the same temperature, the mixture was filtered, and the filtrate was concentrated under reduced pressure. The residue was purified with PTLC (MeOH: $\left.\mathrm{CH}_{2} \mathrm{Cl}_{2}=1: 9\right)$ to give diMOM amine derivative 14a $(2.0 \mathrm{mg}, 65 \%)$ as brown oil. 1H-NMR $\left(400 \mathrm{MHz}, \mathrm{CDCl}_{3}\right) \delta 7.49(1 \mathrm{H}, \mathrm{s}), 5.26(2 \mathrm{H}, \mathrm{s}), 5.16(1 \mathrm{H}, \mathrm{d}$, $J=7.2 \mathrm{~Hz}), 5.07(1 \mathrm{H}, \mathrm{d}, J=6.8 \mathrm{~Hz}), 4.61(1 \mathrm{H}, \mathrm{d}, J=1.2 \mathrm{~Hz}), 4.27(1 \mathrm{H}, \mathrm{ddd}, J=1.2,6.0,7.6 \mathrm{~Hz}), 4.00$ $(2 \mathrm{H}, \mathrm{s}), 3.61(3 \mathrm{H}, \mathrm{s}), 3.50(3 \mathrm{H}, \mathrm{s}), 3.32(3 \mathrm{H}, \mathrm{s}), 2.59(1 \mathrm{H}, \mathrm{br}-\mathrm{s}), 2.03(1 \mathrm{H}, \mathrm{m}), 1.82(1 \mathrm{H}, \mathrm{m}), 1.57(1 \mathrm{H}, \mathrm{m})$, $1.43(1 \mathrm{H}, \mathrm{m}), 1.40-1.25\left(1 \mathrm{H}\right.$, overlapped), $0.91(3 \mathrm{H}, \mathrm{t}, J=6.8 \mathrm{~Hz}) ; 13 \mathrm{C}-\mathrm{NMR}\left(125 \mathrm{MHz}, \mathrm{CDCl}_{3}\right) \delta 162.6$, 152.6, 150.5, 128.1, 120.0, 119.0, 102.4, 95.4, 81.2, 68.5, 57.9, 57.2, 56.8, 42.5, 32.0, 30.9, 30.0, 25.2, 22.9, 14.4.; IR (KBr) 2957, 2925, 2857, 2827, 1726, 1470, 1153, $1005 \mathrm{~cm}^{-1}$; HRMS (ESI) $\mathrm{m} / \mathrm{z}(\mathrm{M}+\mathrm{H})^{+}$calculated for $\left(\mathrm{C}_{20} \mathrm{H}_{32} \mathrm{NO}_{7}\right)^{+}$398.2179, found 398.2178.

\subsubsection{2. (3S,4S)-7-(aminomethyl)-5,8-dihydroxy-4-methoxy-3-pentylisochroman-1-one (14)}

To a solution of diMOM amine derivative $14 \mathrm{a}(4.4 \mathrm{mg}, 11.1 \mu \mathrm{mol})$ in $\mathrm{MeOH}(0.83 \mathrm{~mL})$ was added $6 \mathrm{M}$ aqueous $\mathrm{HCl}(0.28 \mathrm{~mL})$ at $0{ }^{\circ} \mathrm{C}$. After stirring for $5 \mathrm{~h}$ at room temperature, the reaction was quenched by adding saturated aqueous $\mathrm{NaHCO}_{3}$ at $0{ }^{\circ} \mathrm{C}$. The mixture was extracted with the mixture of $\mathrm{MeOH}$ and $\mathrm{CH}_{2} \mathrm{Cl}_{2}\left(\mathrm{MeOH}: \mathrm{CH}_{2} \mathrm{Cl}_{2}=1: 4\right)(\times 4)$ and the combined organic layers were dried over $\mathrm{Na}_{2} \mathrm{SO}_{4}$, filtered and concentrated under reduced pressure. The residue was purified with PTLC ( $\mathrm{MeOH}: \mathrm{CHCl}_{3}$ saturated with $\left.\mathrm{NH}_{3}=1: 9\right)$ to give amiomethyl derivative $\mathbf{1 4}(1.1 \mathrm{mg}, 32 \%)$ as brown solid. m.p. $78-80^{\circ} \mathrm{C} ; 1 \mathrm{H}-\mathrm{NMR}\left(400 \mathrm{MHz}, \mathrm{CDCl}_{3}\right) \delta 6.98(1 \mathrm{H}, \mathrm{s}), 4.59(1 \mathrm{H}, \mathrm{d}, J=1.8 \mathrm{~Hz}), 4.35(1 \mathrm{H}, \mathrm{ddd}$, $J=1.8,6.0,8.0 \mathrm{~Hz}), 3.97(1 \mathrm{H}, \mathrm{d}, J=13.3 \mathrm{~Hz}), 3.88(1 \mathrm{H}, \mathrm{d}, J=13.3 \mathrm{~Hz}), 3.19(3 \mathrm{H}, \mathrm{s}), 1.98(1 \mathrm{H}, \mathrm{m}), 1.83$ $(1 \mathrm{H}, \mathrm{m}), 1.56(1 \mathrm{H}, \mathrm{m}), 1.43(1 \mathrm{H}, \mathrm{m}), 1.40-1.25(4 \mathrm{H}$, overlapped $), 0.90(3 \mathrm{H}, \mathrm{t}, J=7.0 \mathrm{~Hz}) ; 13 \mathrm{C}-\mathrm{NMR}$ $\left(125 \mathrm{MHz}, \mathrm{CDCl}_{3}\right) \delta 169.9,154.2,146.2,130.0,125.8,122.9,108.1,82.8,68.5,56.9,42.3,31.9,30.6,25.1$, 22.8, 14,3.; IR (KBr) 2956, 2921, 2857, 1676, 1441, $1171 \mathrm{~cm}^{-1}$; HRMS (ESI) $\mathrm{m} / z(\mathrm{M}+\mathrm{Na})^{+}$calculated for $\left(\mathrm{C}_{16} \mathrm{H}_{23} \mathrm{NO}_{5} \mathrm{Na}\right)^{+}$332.1474, found 332.1474.

\subsubsection{3. ((3S,4S)-5,8-dihydroxy-4-methoxy-7-nitro-3-pentylisochroman-1-one (15)}

To a solution of $3(28.9 \mathrm{mg}, 89.1 \mu \mathrm{mol})$ in $\mathrm{AcOH}(0.50 \mathrm{~mL})$ was added the mixture of $\mathrm{AcOH}$ and $70 \% \mathrm{HNO}_{3}(0.80 \mathrm{~mL}: 0.20 \mathrm{~mL})$ at $0{ }^{\circ} \mathrm{C}$. After stirring for $10 \mathrm{~min}$ at the same temperature, the reaction was quenched by adding saturated aqueous $\mathrm{NaHCO}_{3}$ at $0{ }^{\circ} \mathrm{C}$. The mixture was extracted with EtOAc $(\times 3)$ and the combined organic layers were washed with saturated aqueous $\mathrm{NaHCO}_{3}$ and brine, dried over $\mathrm{Na}_{2} \mathrm{SO}_{4}$, filtered, and concentrated under reduced pressure. The residue was pathed through $\mathrm{SiO}_{2}$ plug and the resultant mixture of monoMOM nitro derivative $15 \mathrm{a}$ was used for the next reaction without further purification. To a solution of $15 \mathrm{a}$ mixture in $\mathrm{MeOH}(7.5 \mathrm{~mL})$ was added $6 \mathrm{M}$ aqueous $\mathrm{HCl}(2.4 \mathrm{~mL})$ at $0{ }^{\circ} \mathrm{C}$. After stirring for $5 \mathrm{~h}$ at $40^{\circ} \mathrm{C}$, the reaction was quenched by adding saturated aqueous $\mathrm{NaHCO}_{3}$ at $0{ }^{\circ} \mathrm{C}$. The mixture was extracted with EtOAc $(\times 3)$ and the combined organic layers were washed with brine, dried over $\mathrm{Na}_{2} \mathrm{SO}_{4}$, filtered, and concentrated under reduced pressure. The residue was purified with PTLC (EtOAc: $n$-hexane $=1: 1)$ to give nitro derivative $\mathbf{1 5}(21.5 \mathrm{mg}, 74 \%)$ as a yellow solid. m.p. 158-159; 1H-NMR $\left(400 \mathrm{MHz}, \mathrm{CDCl}_{3}\right) \delta 11.89(1 \mathrm{H}, \mathrm{s}), 7.78(1 \mathrm{H}, \mathrm{s}), 6.80(1 \mathrm{H}, \mathrm{br}-\mathrm{s})$, $4.82(1 \mathrm{H}, \mathrm{d}, J=2.6 \mathrm{~Hz}), 4.55(1 \mathrm{H}, \mathrm{ddd}, J=2.6,5.2,8.3 \mathrm{~Hz}), 3.46(3 \mathrm{H}, \mathrm{s}), 1.96(1 \mathrm{H}, \mathrm{m}), 1.86(1 \mathrm{H}, \mathrm{m})$, $1.59(1 \mathrm{H}, \mathrm{m}), 1.47(1 \mathrm{H}, \mathrm{m}), 1.40-1.25(4 \mathrm{H}$, overlapped), $0.91(3 \mathrm{H}, \mathrm{t}, J=7.1 \mathrm{~Hz}) ; 13 \mathrm{C}-\mathrm{NMR}(125 \mathrm{MHz}$, $\left.\mathrm{CDCl}_{3}\right) \delta 167.5,150.4,144.9,137.6,129.4,119.7,110.7,81.0,70.3,57.6,31.4,29.4,24.7,22.4,14.0$; IR (KBr) 3416, 2962, 2927, 2857, 1679, 1445, 1261, 1018, $800 \mathrm{~cm}^{-1}$; HRMS (ESI) $\mathrm{m} / z(\mathrm{M}+\mathrm{H})^{+}$calculated for $\left(\mathrm{C}_{15} \mathrm{H}_{20} \mathrm{NO}_{7}\right)^{+} 326.1240$, found 326.1224 . 
3.1.24. (3S,4S)-7-amino-5,8-dihydroxy-4-methoxy-3-pentylisochroman-1-one (16)

To a solution of nitro derivative $\mathbf{1 5}(5.0 \mathrm{mg}, 15.4 \mu \mathrm{mol})$ in THF $(0.62 \mathrm{~mL})$ and $\mathrm{MeOH}(80 \mu \mathrm{L})$ was added $\mathrm{PtO}_{2}(0.3 \mathrm{mg}, 1.54 \mu \mathrm{mol})$ at room temperature. After stirring for $1.5 \mathrm{~h}$ at the same temperature under hydrogen atmosphere $(1 \mathrm{~atm})$, the mixture was passed through a membrane filter to remove $\mathrm{PtO}_{2}$. The mixture was concentrated under reduced pressure and the residue was purified with PTLC (EtOAc: $n$-hexane $=3: 7$, developed by three times) to give nitro derivative $\mathbf{1 6}(4.3 \mathrm{mg}, 95 \%)$ as a yellow solid. m.p. $118-119^{\circ} \mathrm{C} ; 1 \mathrm{H}-\mathrm{NMR}\left(500 \mathrm{MHz}, \mathrm{CDCl}_{3}\right) \delta 10.72(1 \mathrm{H}, \mathrm{s}), 6.45(1 \mathrm{H}, \mathrm{s}), 5.68(1 \mathrm{H}, \mathrm{br}-\mathrm{s}), 4.67$ $(1 \mathrm{H}, \mathrm{d}, J=2.5 \mathrm{~Hz}), 4.46(1 \mathrm{H}, \mathrm{ddd}, J=2.5,5.5,8.3 \mathrm{~Hz}), 4.05(1 \mathrm{H}, \mathrm{br}-\mathrm{s}), 3.32(3 \mathrm{H}, \mathrm{s}), 1.94(1 \mathrm{H}, \mathrm{m}), 1.84$ $(1 \mathrm{H}, \mathrm{m}), 1.75-1.50(1 \mathrm{H}$, overlapped), $1.45(1 \mathrm{H}, \mathrm{m}), 1.40-1.25(4 \mathrm{H}$, overlapped $), 0.90(3 \mathrm{H}, \mathrm{t}, J=7.0 \mathrm{~Hz})$; 13C-NMR (125 MHz, $\left.\mathrm{CDCl}_{3}\right) \delta 169.8,145.9,144.5,137.2,109.8,108.4,106.8,82.4,69.1,56.1,31.6,30.1$, 24.9, 22.5, 14.0; IR (KBr) 3378, 2957, 2926, 2858, 1681, 1464, 1217, $1171 \mathrm{~cm}^{-1}$; HRMS (ESI) $m / z(\mathrm{M}+\mathrm{Na})^{+}$ calculated for $\left(\mathrm{C}_{15} \mathrm{H}_{21} \mathrm{NO}_{5} \mathrm{Na}\right)^{+} 318.1317$, found 318.1321.

3.1.25. (3S,4S)-7-chloro-8-hydroxy-4-methoxy-5-(methoxymethoxy)-3-pentylisochroman-1-one (18a)

To a solution of $3(5.0 \mathrm{mg}, 15.4 \mu \mathrm{mol})$ in DMF $(0.18 \mathrm{~mL})$ was added the solution of $N$-chlorosuccinimide $(4.1 \mathrm{mg}, 30.8 \mu \mathrm{mol})$ in DMF $(31 \mu \mathrm{L})$ at room temperature. After stirring for $5 \mathrm{~h}$ at $65^{\circ} \mathrm{C}$, the reaction was quenched by adding saturated aqueous $\mathrm{NaHCO}_{3}$ at $0{ }^{\circ} \mathrm{C}$. The mixture was extracted with EtOAc $(\times 3)$ and the combined organic layers were washed with brine, dried over $\mathrm{Na}_{2} \mathrm{SO}_{4}$, filtered, and concentrated under reduced pressure. The residue was purified with PTLC (EtOAc: $n$-hexane $=1: 9)$ to give monoMOM chloro derivative 18 a $(3.3 \mathrm{mg}, 60 \%)$ as a brown solid. m.p. 79-81 ${ }^{\circ} \mathrm{C}$; $1 \mathrm{H}-\mathrm{NMR}\left(400 \mathrm{MHz}, \mathrm{CDCl}_{3}\right) \delta 11.23(1 \mathrm{H}, \mathrm{s}), 7.55(1 \mathrm{H}, \mathrm{s}), 5.18(1 \mathrm{H}, \mathrm{d}, J=7.0 \mathrm{~Hz}), 5.16(1 \mathrm{H}, \mathrm{d}$, $J=7.0 \mathrm{~Hz}), 4.59(1 \mathrm{H}, \mathrm{d}, J=1.7 \mathrm{~Hz}), 4.39(1 \mathrm{H}, \mathrm{ddd}, J=1.7,6.0,8.0 \mathrm{~Hz}), 3.50(3 \mathrm{H}, \mathrm{s}), 3.30(3 \mathrm{H}, \mathrm{s}), 2.07$ $(1 \mathrm{H}, \mathrm{m}), 1.86(1 \mathrm{H}, \mathrm{m}), 1.70-1.50(1 \mathrm{H}$, overlapped $), 1.47(1 \mathrm{H}, \mathrm{m}), 1.45-1.25(4 \mathrm{H}$, overlapped $), 0.92(3 \mathrm{H}, \mathrm{t}$, $J=7.1 \mathrm{~Hz}) ; 13 \mathrm{C}-\mathrm{NMR}\left(125 \mathrm{MHz}, \mathrm{CDCl}_{3}\right) \delta 168.7,152.8,146.3,125.1,123.6,123.0,109.0,95.7,82.7,67.4$, 56.8, 56.4, 31.5, 30.4, 24.7, 22.5, 14.0.; IR (KBr) 2955, 2927, 2853, 2826, 1681, 1453, 1433, $1206 \mathrm{~cm}^{-1}$; HRMS (ESI) $\mathrm{m} / z(\mathrm{M}+\mathrm{Na})^{+}$calculated for $\left(\mathrm{C}_{17} \mathrm{H}_{23} \mathrm{O}_{6} \mathrm{ClNa}\right)^{+}$381.1081, found 381.1088.

3.1.26. (3S,4S)-7-chloro-5,8-dihydroxy-4-methoxy-3-pentylisochroman-1-one (18)

To a solution of monoMOM chloro derivative 18a (3.3 mg, $9.20 \mu \mathrm{mol})$ in $\mathrm{MeOH}(0.69 \mathrm{~mL})$ was added $6 \mathrm{M}$ aqueous $\mathrm{HCl}(0.23 \mathrm{~mL})$ at $0{ }^{\circ} \mathrm{C}$. After stirring for $2 \mathrm{~h}$ at $40^{\circ} \mathrm{C}$, the reaction was quenched by adding saturated $\mathrm{NaHCO}_{3}$ at $0{ }^{\circ} \mathrm{C}$. The mixture was extracted with EtOAc $(\times 3)$ and the combined organic layers were washed with brine, dried over $\mathrm{Na}_{2} \mathrm{SO}_{4}$, filtered, and concentrated under reduced pressure. The residue was purified with PTLC (EtOAc: $n$-hexane $=1: 9)$ to give chloro derivative 18 ( $2.1 \mathrm{mg}, 73 \%$ ) as a brown solid. m.p. $119-120{ }^{\circ} \mathrm{C} ; 1 \mathrm{H}-\mathrm{NMR}\left(400 \mathrm{MHz}, \mathrm{CDCl}_{3}\right) \delta 11.17(1 \mathrm{H}, \mathrm{br}-\mathrm{s}), 7.34$ $(1 \mathrm{H}, \mathrm{s}), 6.34(1 \mathrm{H}, \mathrm{br}-\mathrm{s}), 4.82(1 \mathrm{H}, \mathrm{br}-\mathrm{s}), 4.59(1 \mathrm{H}, \mathrm{ddd}, J=2.8,5.6,8.4 \mathrm{~Hz}), 3.48(3 \mathrm{H}, \mathrm{s}), 2.03(1 \mathrm{H}, \mathrm{m})$, $1.93(1 \mathrm{H}, \mathrm{m}), 1.64(1 \mathrm{H}, \mathrm{m}), 1.53(1 \mathrm{H}, \mathrm{m}), 1.51-1.35(4 \mathrm{H}$, overlapped $), 0.98(3 \mathrm{H}, \mathrm{t}, J=7.2 \mathrm{~Hz}) ; 13 \mathrm{C}-\mathrm{NMR}$ $\left(100 \mathrm{MHz}, \mathrm{CDCl}_{3}\right) \delta 168.7,152.1,145.6,124.9,122.8,121.1,108.5,81.8,69.6,57.0,31.5,29.8,24.8,22.5$, 14.0.; IR (KBr) 3282, 2958, 2929, 2860, 1681, 1437, $1198 \mathrm{~cm}^{-1}$; HRMS (ESI) $m / z(\mathrm{M}+\mathrm{H})^{+}$calculated for $\left(\mathrm{C}_{15} \mathrm{H}_{20} \mathrm{O}_{5} \mathrm{Cl}\right)^{+}$315.0999, found 315.0998.

\subsubsection{7. (3S,4S)-7-bromo-5,8-dihydroxy-4-methoxy-3-pentylisochroman-1-one (19)}

To a solution of bromo derivative $2(11.0 \mathrm{mg}, 24.6 \mu \mathrm{mol})$ in $\mathrm{MeOH}(1.8 \mathrm{~mL})$ was added $6 \mathrm{M}$ aqueous $\mathrm{HCl}(0.62 \mathrm{~mL})$ at $0{ }^{\circ} \mathrm{C}$. After stirring for $3.5 \mathrm{~h}$ at $40^{\circ} \mathrm{C}$, the reaction was quenched by adding saturated aqueous $\mathrm{NaHCO}_{3}$ at $0{ }^{\circ} \mathrm{C}$. The mixture was extracted with EtOAc $(\times 3)$ and the combined organic layers were washed with brine, dried over $\mathrm{Na}_{2} \mathrm{SO}_{4}$, filtered, and concentrated under reduced pressure. The residue was purified with PTLC (EtOAc: $n$-hexane $=1: 9)$ to give bromo derivative 19 $(8.6 \mathrm{mg}, 97 \%)$ as a white solid. m.p. $132{ }^{\circ} \mathrm{C}$; $1 \mathrm{H}-\mathrm{NMR}\left(400 \mathrm{MHz}, \mathrm{CDCl}_{3}\right) \delta 11.26(1 \mathrm{H}, \mathrm{s}), 7.36(1 \mathrm{H}, \mathrm{s})$, $6.00(1 \mathrm{H}, \mathrm{br}-\mathrm{s}), 4.76(1 \mathrm{H}, \mathrm{d}, J=2.7 \mathrm{~Hz}), 4.52(1 \mathrm{H}, \mathrm{ddd}, J=2.7,5.1,8.3 \mathrm{~Hz}), 3.41(3 \mathrm{H}, \mathrm{s}), 1.95(1 \mathrm{H}, \mathrm{m})$, $1.86(1 \mathrm{H}, \mathrm{m}), 1.70-1.50(2 \mathrm{H}$, overlapped), $1.40-1.25(4 \mathrm{H}$, overlapped $), 0.91(3 \mathrm{H}, \mathrm{t}, J=7.0 \mathrm{~Hz}) ; 13 \mathrm{C}-\mathrm{NMR}$ 
$\left(125 \mathrm{MHz}_{,} \mathrm{CDCl}_{3}\right) \delta 168.4,153.0,145.8,127.9,121.5,111.6,108.2,81.4,70.0,57.0,31.5,29.6,24.8,22.5$, 14.0.; IR (KBr) 3296, 2955, 2930, 2859, 1679, 1432, $1197 \mathrm{~cm}^{-1}$; HRMS (ESI) $\mathrm{m} / \mathrm{z}(\mathrm{M}+\mathrm{Na})^{+}$calculated for $\left(\mathrm{C}_{15} \mathrm{H}_{19} \mathrm{O}_{5} \mathrm{BrNa}\right)^{+}$381.0314, found 381.0322 .

\subsubsection{8. (3S,4S)-5,8-dihydroxy-7-iodo-4-methoxy-3-pentylisochroman-1-one (20)}

To a solution of $3(12.6 \mathrm{mg}, 38.8 \mu \mathrm{mol})$ in DMF $(0.35 \mathrm{~mL})$ was added the solution of $N$-iodosuccinimide $(17.5 \mathrm{mg}, 77.6 \mu \mathrm{mol})$ in DMF $(50 \mu \mathrm{L})$ at room temperature. After stirring for $3 \mathrm{~h}$ at room temperature, the reaction was quenched by adding saturated aqueous $\mathrm{NaHCO}_{3}$ at $0{ }^{\circ} \mathrm{C}$. The mixture was extracted with $\mathrm{CH}_{2} \mathrm{Cl}_{2}(\times 3)$ and the combined organic layers were washed with brine, dried over $\mathrm{Na}_{2} \mathrm{SO}_{4}$, filtered, and concentrated under reduced pressure. The residue was pathed through $\mathrm{SiO}_{2}$ plug and the resultant mixture of monoMOM iodo derivative 20a was used for the next reaction without further purification. To a solution of crude mixture of 20a in $\mathrm{MeOH}(0.83 \mathrm{~mL})$ was added $6 \mathrm{M}$ aqueous $\mathrm{HCl}(0.30 \mathrm{~mL})$ at $0{ }^{\circ} \mathrm{C}$. After stirring for $5 \mathrm{~h}$ at $40^{\circ} \mathrm{C}$, the reaction was quenched by adding saturated aqueous $\mathrm{NaHCO}_{3}$ at $0{ }^{\circ} \mathrm{C}$. The mixture was extracted with EtOAc $(\times 3)$ and the combined organic layers were washed with brine, dried over $\mathrm{Na}_{2} \mathrm{SO}_{4}$, filtered, and concentrated under reduced pressure. The residue was purified with PTLC (EtOAc: $n$-hexane $=1: 9$ ) to give iodo derivative 20 (4.0 mg, 87\%) as a pale-yellow oil. m.p. $109-110{ }^{\circ} \mathrm{C} ; 1 \mathrm{H}-\mathrm{NMR}\left(500 \mathrm{MHz}, \mathrm{CDCl}_{3}\right) \delta 11.44(1 \mathrm{H}, \mathrm{s})$, $7.57(1 \mathrm{H}, \mathrm{s}), 6.11(1 \mathrm{H}, \mathrm{br}-\mathrm{s}), 4.51(1 \mathrm{H}, \mathrm{ddd}, J=2.8,5.4,8.5 \mathrm{~Hz}), 3.40(3 \mathrm{H}, \mathrm{s}), 1.94(1 \mathrm{H}, \mathrm{m}), 1.85(1 \mathrm{H}, \mathrm{m})$, 1.75-1.50 (4H, overlapped), $1.45(1 \mathrm{H}, \mathrm{m}), 1.40-1.30$ (4H, overlapped), $0.91(3 \mathrm{H}, \mathrm{t}, J=7.0 \mathrm{~Hz}) ; 13 \mathrm{C}-\mathrm{NMR}$ $\left(125 \mathrm{MHz}_{,} \mathrm{CDCl}_{3}\right) \delta 168.3,155.3,146.3,133.8,122.6,107.1,85.5,81.5,69.8,56.9,31.5,29.7,24.8,22.5$, 14.0; IR (KBr) 3293, 2977, 298, 2857, 1674, 1427, $1197 \mathrm{~cm}^{-1}$; HRMS (ESI) $\mathrm{m} / z(\mathrm{M}+\mathrm{Na})^{+}$calculated for $\left(\mathrm{C}_{15} \mathrm{H}_{19} \mathrm{O}_{5} \mathrm{Ina}\right)^{+} 429.0175$, found 429.0174 .

\subsection{Bactericidal Assay}

Methicillin-susceptible Staphylococcus aureus (MSSA) ATCC25923 and methicillin-resistant Staphylococcus aureus (MRSA) ATCC 33,591 were aerobically incubated at $37{ }^{\circ} \mathrm{C}$ in Luria-Bertani medium (LB, Nippon Becton Dickinson Company, Tokyo, Japan). Porphyromonas gingivalis W83 was anaerobically incubated at $37^{\circ} \mathrm{C}$ in Gifu anaerobic medium (GAM, Nissui, Tokyo, Japan). Each culture $(20 \mu \mathrm{L})$ prepared to an optical density of 1.5 at $600 \mathrm{~nm}$ were appropriately incubated with various concentrations of synthesized compounds in $200 \mu \mathrm{L}$ of culture medium at $37^{\circ} \mathrm{C}$ for $24 \mathrm{~h}$ in 96 -well plate (Thermo scientific, MA, USA). Compounds were dissolved in DMSO (Wako, Osaka, Japan). The degree of turbidity in the broth culture was measured at absorbance $600 \mathrm{~nm}$ using microplate reader (Thermo scientific, MA, USA).

\subsection{Cellular Toxicity}

Human lung adenocarcinoma epithelial cell line A549 cells were cultured at $37^{\circ} \mathrm{C}$ in growth medium (DMEM with 10\% fetal bovine serum) in 5\% $\mathrm{CO}_{2}$, and then seeded into 96-well plates at a density of $1 \times 10^{5}$ cells $/ \mathrm{mL}$. Once the cells reached $80 \%-90 \%$ confluence, they were treated with or without $10 \mu \mathrm{M}$ of various compounds at $37^{\circ} \mathrm{C}$ for $12 \mathrm{~h}$. Next, $10 \mu \mathrm{L}$ Cell Counting Kit-8 (Dojindo Molecular Technologies, Kumamoto, Japan) solution was added to each well, and the plate was incubated for $2 \mathrm{~h}$ at $37^{\circ} \mathrm{C}$. Cell viability was determined by measuring the absorbance at $450 \mathrm{~nm}$ using a fluorimeter (Varioscan, Thermo, USA).

\section{Conclusions}

We constructed a chemical library of the side-chain derivatives of eurotiumide A, which is a dihydroisocoumarin-type marine natural product. The antimicrobial evaluation of these compounds was conducted against MSSA, MRSA, and P. gingivalis. We discovered several compounds to be effective against these strains; among them, the isopentyl derivative 6 is especially more active against all three strains than $\mathbf{1}$. Continuous research to clarify the modes of action of these derivatives is under way in our laboratory. 
Supplementary Materials: The following are available online at http://www.mdpi.com/1660-3397/18/2/92/s1, 1Hand 13C-NMR charts of all new compounds.

Author Contributions: A.N. conceived and designed this research and analyzed the experimental data; H.S., T.N., M.H., S.N., and S.K. (Shuhei Kameyama) prepared compounds and collected their spectral data; S.K. (Sangita Karanjit) checked the experimental data; Y.F., N.H., G.K. and M.O. evaluated the antimicrobial activity; A.N., M.O. and K.N. wrote the paper; all of the authors reviewed and approved the manuscript. All authors have read and agreed to the published version of the manuscript.

Funding: This work was supported by JSPS KAKENHI Grant Nos. 17K08365 (A.N.), 18H02657 (M.O.), JP19H02851 (K.N.), and JP16H01156 (K.N.), as well as the Kurita Water and Environment Foundation. We also acknowledge Tokushima University for their financial support of the Research Clusters program of Tokushima University (No. 1802001).

Conflicts of Interest: The authors declare no conflict of interest.

\section{References}

1. Ma, B.; Forney, L.; Ravel, J. Vaginal microbiology: Rethinking health and disease. Annu. Rev. Microbiol. 2012, 66, 371-389. [CrossRef] [PubMed]

2. Buffie, C.G.; Parker, E.G. Microbiota-mediated colonization resistance against intestinal pathogens. Nat. Rev. Immunol. 2013, 13, 790-801. [CrossRef] [PubMed]

3. MCKenney, P.T.; Palmer, E.G. From hype to hope: The gut microbiome in Health and Disease. Cell 2015, 163, 1326-1332. [CrossRef] [PubMed]

4. Lynch, S.V.; Petersen, O. The Human Intestinal Microbiome in Health and Disease. N. Eng. J. M. 2016, 375, 371-389. [CrossRef] [PubMed]

5. Ma, W.H.; Piters, W.A.A.S.; Bogaert, D. The microbiota of the respiratory tract: Gatekeeper to respiratory health. Nat. Rev. Microbiol. 2017, 13, 259-270.

6. Lewis, K. Platforms for Antibiotic Discovery. Nat. Rev. Drug Discovery 2013, 12, 371-387. [CrossRef] [PubMed]

7. Becattini, S.; Taru, Y.; Palmer, E.G. Antibiotic-induced changes in the intestinal microbiota and disease. Trends Mol. Med. 2016, 22, 458-478. [CrossRef]

8. Brown, E.D.; Wright, G.D. Antibacterial Drug Discovery in the Resistance Era. Nature 2016, 529, $336-343$. [CrossRef]

9. Fleming, A. On the antibacterial action of cultures of a penicillium with special reference to their use in the isolation of B. influenzae. Br. J. Exp. Pathol. 1929, 10, 226-236. [CrossRef]

10. Chu, D.T.W.; Plattner, J.J.; Katz, L. New Directions in Antibacterial Research. J. Med. Chem. 1996, 39, 3853-3874. [CrossRef]

11. Saleem, M.; Nazir, M.; Ali, M.S.; Hussain, H.; Lee, Y.S.; Riaz, N.; Jabbar, A. Antimicrobial natural products: An update on future antibiotic drug candidates. Nat. Prod. Rep. 2010, 27, 238-254. [CrossRef] [PubMed]

12. Bologa, C.G.; Ursu, O.; Oprea, T.I.; Melancon, C.E., III; Tegos, G.P. Emerging trends in the discovery of natural product antibacterials. Curr. Opin. Pharmacol. 2013, 13, 678-687. [CrossRef] [PubMed]

13. Butler, M.S.; Robertson, A.A.B.; Cooper, M.A. Natural product and natural product derived drugs in clinical trials. Nat. Prod. Rep. 2014, 31, 1612-1661. [CrossRef]

14. Szychowski, J.; Truchon, J.-F.; Bennani, Y.L. Natural Products in Medicine: Transformational Outcome of Synthetic Chemistry. J. Med. Chem. 2014, 57, 9292-9308. [CrossRef] [PubMed]

15. Sclinke, C.; Martins, T.; Queiroz, S.C.; Melo, I.S.; Reyes, F.G.R. Antibacterial Compounds from Marine Bacteria, 2010-2015. J. Nat. Prod. 2017, 80, 1215-1228. [CrossRef] [PubMed]

16. Masscheletin, J.; Henner, M.; Challis, G.L. Antibiotics from Gram-negative bacteria: A comprehensive overview and selected biosynthetic highlights. Nat. Prod. Rep. 2017, 34, 712-783. [CrossRef]

17. Von Nussbaum, F.; Brands, M.; Hizen, B.; Weigand, S.; Habich, D. Antibacterial natural products in medicinal chemistry-exodus or revival? Angew, Chem. Int. Ed. 2006, 45, 5072-5129. [CrossRef]

18. Clardy, J.; Fischbach, M.A.; Walsh, C.T. New antibiotics from bacterial natural product. Nat. Biotechnol. 2006, 24, 1541-1550. [CrossRef]

19. Abouelhassan, Y.; Garrison, A.T.; Yang, H.; Riveros, A.C.; Burch, G.M.; Huigens, R.W., III. Recent Progress in Natural-Product-Inspired Progra,s Aimed To Address Antibiotic Resistance and Tolerance. J. Med. Chem. 2019, 62, 7618-7642. [CrossRef] 
20. Blair, J.M.; Webber, M.A.; Baylay, A.J.; Ogbolu, D.O.; Piddock, L.J.V. Molecular Mechanisms of Antibiotic Resistance. Nat. Rev. Microbiol. 2015, 13, 42-51. [CrossRef]

21. Ali, J.; Rafiq, Q.A.; Ratcliffe, E. Antimicrobial Resistance Mechanisms and Potential Synthetic Treatments. Futur. Sci. OA 2018, 4, FSO290. [CrossRef]

22. Francino, M.P. Antibiotics and the human gut microbiome: Dysbioses and accumulation of resistances. Front. Microbiol. 2016, 6, 1543. [CrossRef] [PubMed]

23. Chen, M.; Shao, C.-L.; Wang, K.-L.; Xu, Y.; She, Z.-G.; Wang, C.-Y. Dihydroisocoumarin derivatives with antifouling activities from a gorgonian-derived Eurotium sp. fungus. Tetrahedron 2014, 70, 9132-9138. [CrossRef]

24. Nakayama, A.; Sato, H.; Karanjit, S.; Hayashi, N.; Oda, M.; Namba, K. Asymmetric Total Syntheses and Structure Revisions of Eurotiumide A and Eurotiumide B, and Their Evaluation as Natural Fluorescent Probes. Eur. J. Org. Chem. 2018. [CrossRef]

25. Nakayama, A.; Sato, H.; Nagano, S.; Karanjit, S.; Imagawa, H.; Namba, K. Asymmetric Total Syntheses and Structure Elucidations of (+)-Eurtiumide F and (+)-Eurotiumide G. Chem. Pharm. Bull. 2019, 67, 953-958. [CrossRef] [PubMed]

26. Katayama, Y.; Ito, T.; Hiramatsu, K. A new class of genetic element, Staphylococcus cassette chromosome mec, encodes methicillin resistance in Staphylococcus aureus. Antimicrob. Agents Chemother. 2000, 44, 1549-1555. [CrossRef]

(C) 2020 by the authors. Licensee MDPI, Basel, Switzerland. This article is an open access article distributed under the terms and conditions of the Creative Commons Attribution (CC BY) license (http://creativecommons.org/licenses/by/4.0/). 